\title{
Sea-ice retreat may decrease carbon export and vertical microbial connectivity in the Eurasian Arctic basins
}

Eduard Fadeev ( $\boldsymbol{\nabla}$ dr.eduard.fadeev@gmail.com )

University of Vienna https://orcid.org/0000-0002-2289-2949

\section{Andreas Rogge}

Alfred Wegener Institute, Helmholtz Center for Polar and Marine Research https://orcid.org/0000-00024036-4082

\section{Simon Ramondenc}

Alfred Wegener Institute Helmholtz Center for Polar and Marine Research

\section{Eva-Maria Nöthig}

Alfred Wegener Institute, Helmholtz Center for Polar and Marine Research https://orcid.org/0000-0002-

7527-7827

\section{Claudia Wekerle}

Alfred Wegener Institute Helmholtz Center for Polar and Marine Research

\section{Christina Bienhold}

Max Planck Institute for Marine Microbiology

\section{lan Salter}

Faroe Marine Research Institute https://orcid.org/0000-0002-4513-0314

\section{Anya Waite}

Ocean Frontier Institute

\section{Laura Hehemann}

Alfred Wegener Institute for Polar and Marine Research

\section{Antje Boetius}

Alfred Wegener Institute for Polar and Marine Research https://orcid.org/0000-0003-2117-4176

\section{Morten Iversen}

Alfred Wegener Institute for Polar and Marine Research

\section{Article}

Keywords: deep sea, vertical export, particle flux, marine snow, polar microbes, climate change impact

Posted Date: December 1st, 2020

DOI: https://doi.org/10.21203/rs.3.rs-101878/v1 
License: (c) (i) This work is licensed under a Creative Commons Attribution 4.0 International License. Read Full License

Version of Record: A version of this preprint was published at Communications Biology on November 3rd, 2021. See the published version at https://doi.org/10.1038/s42003-021-02776-w. 


\section{Sea-ice retreat may decrease carbon export and vertical microbial}

\section{connectivity in the Eurasian Arctic basins}

1 Eduard Fadeev ${ }^{1,2, \#^{*},}$ Andreas Rogge ${ }^{1,3}$, Simon Ramondenc ${ }^{1}$, Eva-Maria Nöthig ${ }^{1}$, Claudia

2 Wekerle $^{1}$, Christina Bienhold ${ }^{1,2}$, Ian Salter ${ }^{1,4}$, Anya M. Waite ${ }^{1,5}$, Laura Hehemann ${ }^{1}$, Antje

3 Boetius $^{1,2,6}$, Morten H. Iversen ${ }^{1,6^{*}}$

$4{ }^{1}$ Alfred Wegener Institute, Helmholtz Center for Polar and Marine Research, D-27570 Bremerhaven,

5 Germany

$6 \quad{ }^{2}$ Max Planck Institute for Marine Microbiology, D-28359 Bremen, Germany

$7 \quad{ }^{3}$ Institute for Ecosystem Research, Kiel University, D-24118 Kiel, Germany

$8{ }^{4}$ Faroe Marine Research Institute, FO 100 Tórshavn, Faroe Islands

$9{ }^{5}$ Ocean Frontier Institute, NS B3H 4R2 Halifax, Canada

$10{ }^{6}$ MARUM and University of Bremen, D-28359 Bremen, Germany

11 \#Present address: Department of Functional and Evolutionary Ecology, University of Vienna, A-1090

12 Vienna, Austria

13 Corresponding Authors:

14 Eduard Fadeev - eduard.fadeev@univie.ac.at

15 Morten H. Iversen - morten.iversen@awi.de

16 Keywords: deep sea, vertical export, particle flux, marine snow, polar microbes, climate change

17 impact

18 Abstract

Arctic Ocean sea-ice cover is shrinking due to warming. Long-term sediment trap data show higher export efficiency of particulate organic carbon in regions with seasonal sea-ice compared to regions without sea-ice. To investigate this sea-ice enhanced export, we compared how different phytoplankton communities in seasonally ice-free and ice-covered regions of the Fram Strait affect carbon export and vertical dispersal of microbes. In situ collected aggregates, combined with microbial source tracking revealed that larger aggregates from sea-ice and under-ice diatom blooms were responsible for higher export efficiency and vertical microbial connectivity. During early summer, Phaeocystis aggregates dominated the ice-free regions and exported two-fold less carbon than diatom aggregates in ice-covered regions, and also less surface-born microbial clades to the deep-sea. This suggests that continuous ice-loss will further decrease pelagic-benthic coupling, impacting the quantity and quality of food input due to formation of slow-settling aggregates, with potential repercussions for Arctic deep-sea ecosystems. 
32 The Arctic Ocean is currently undergoing unprecedented changes due to ongoing climate warming. 33 Ice coverage is declining by $\sim 13 \%$ per decade compared to the mean September extent for 1981$2010^{1}$, and climate models project that business-as-usual scenarios will result in seasonally ice-free conditions by $2050^{2}$. Increasing temperature, combined with declining sea-ice extent, ice thickness and multiyear ice $^{3}$ are impacting the composition of primary producers in the Arctic Ocean ${ }^{4}$. For example, Atlantic phytoplankton species, such as Phaeocystis spp., are already seasonally reoccurring in the Fram Strait ${ }^{5}$, and were also recently observed during a phytoplankton bloom in the central Arctic Ocean ${ }^{6}$. It has been suggested that temperate phytoplankton species will become resident in the Eurasian basins of the Arctic Ocean if the intrusion of warming Atlantic waters continues $^{7}$. As primary producers form the base of the food web, such shifts are likely to have drastic consequences, not just in the pelagic realm, but also for pelagic-benthic coupling and biogeochemical cycling in the Arctic Ocean ${ }^{8}$. However, the complexity of factors driving Arctic productivity regionally makes it difficult to generalize to the future carbon flux in the entire Arctic Ocean ${ }^{9}$.

Remote sensing of ocean color in the Arctic shelf seas suggests an increase in net primary production by $57 \%$ since $1998^{10}$, which likely enhances vertical carbon and nutrient fluxes ${ }^{11}$. Furthermore, the transformation from thick multiyear to thin first year ice is increasing light transmission through the ice $^{12}$. Accordingly, field observations show an increased spatial and temporal extent of sea-ice algae and under-ice pelagic phytoplankton in the Arctic basins, for which ocean color based PP assessments are not available ${ }^{6,13-15}$. When the ice melts, such ice-algae and under-ice phytoplankton blooms that are mostly composed of diatoms can also deliver substantial pulses of carbon and nutrients to benthic ecosystems ${ }^{8,16,17}$. For example in 2012, the release of the fast-sinking ice-algae, Melosira spp., from melting sea-ice delivered up to $9 \mathrm{~g}$ of carbon per square meter of seafloor, which was more than $85 \%$ of the total carbon export that year ${ }^{16}$. Primary production models suggest that with the northward propagation of ice-edge blooms along leads and polynyas, the impact of ice-algae and under-ice phytoplankton blooms on productivity is likely to increase ${ }^{18}$, with ecological consequences for pelagic and benthic ecosystems ${ }^{16,19}$. However, it remains unclear what ecological effects an earlier and spatially substantial retreat of the ice-edge will have for carbon export on the Arctic shelf seas and margins. Key factors could be timing of stratification, e.g. by meltwater, the phytoplankton composition during the bloom, mismatches to grazers, and other effects on carbon export efficiency, including the microbial loop in the euphotic zone and remineralization of aggregates during sinking to deep-waters.

61

It is well established that sinking particles are an essential conduit of carbon and nutrients to

64 heterotrophic organisms in the deep ocean ${ }^{20}$. The microbial loop retains most carbon and nutrients in the surface ocean, and can influence carbon export efficiency substantially, next to other factors such as particle sizes and the activities of grazers ${ }^{21}$. Recent studies have also revealed that particles are vectors that disperse microbes from the surface to the deep ocean some of which may carry specific heterotrophic functions in the remineralization of sinking matter ${ }^{22-24}$. Hence, sinking particles can play a key role in determining the structure and functioning of deep-sea microbial communities beyond supply of energy and nutrients ${ }^{22,23}$. To date, such so-called vertical microbial connectivity has mainly been demonstrated in temperate and tropical oceanic settings ${ }^{22-26}$. However, Rapp et al. (2018) found that sedimentation of sea-ice algae influences microbial community composition at the seafloor in the central Arctic. Considering the changes that the Arctic Ocean is currently undergoing, it is critical to understand how microbial connectivity and carbon export will be impacted by changing ice regimes and associated alterations in the composition and rates of primary producers. 
Here, we assess the efficiency of particle export and vertical connectivity in the Fram Strait under seasonally ice-covered and ice-free conditions, which were defined based on temporal duration of sea-ice presence during the productive season. The Fram Strait represents the major deep-water gateway to the Arctic Ocean basins. Warm Atlantic water flows northwards via the West Spitzbergen Current (WSC) through the eastern part of Fram Strait, whereas cold Arctic water and sea-ice flows southwards into the Atlantic via the East Greenland Current (EGC) in its western part (Fig. 1a). The annual ice volume export through the western Fram Strait is currently increasing by $11 \%$ per decade during spring and summer due to ice thinning and increasing drift speed ${ }^{27}$. If Atlantic warming of the Arctic Ocean continues, it is projected that stronger ice-melt will occur in the western Eurasian Basin, eventually reducing ice export through Fram Strait ${ }^{28}$. Here we studied the effect of sea-ice distribution on phytoplankton community composition, carbon export efficiency and vertical microbial connectivity in the Fram Strait. We test the hypotheses 1) that settling aggregates formed in ice-covered regions sink faster than those formed in ice-free regions, which may result in lower export flux for ice-free regions. With regard to the effect on microbial community structure we postulated that 2) particle-associated microbes originate from surface waters and have little exchange with free-living microbes at depth, 3) that there is stronger vertical microbial connectivity in icecovered compared to ice-free regions, and 4) that the stronger microbial connectivity leads to higher representation of surface-born microbes in the deep-sea including sediments. We found that large and fast-settling diatom aggregates in ice-covered regions resulted in higher carbon export efficiency near the ice and thus stronger vertical microbial connectivity compared to the seasonally ice-free region of the Fram Strait, which was dominated by smaller, slow-sinking Phaeocystis spp. aggregates. Our results suggest that with the ice-edge seasonally retreating from the Eurasian basins, carbon export efficiency and vertical connectivity may decline in large regions of the Arctic Ocean.

\section{Results}

\section{Settling aggregates in ice-free and ice-covered regions}

We studied microbial communities associated with settling aggregates in contrasting sea-ice conditions between June $24^{\text {th }}$ and July $16^{\text {th }} 2016$ at the Long-Term Ecological Research (LTER) observatory HAUSGARTEN in the Fram Strait (Expedition PS99.2 with RV POLARSTERN). We classified ice concentration $>15 \%$ as ice-covered conditions and ice concentration $<15 \%$ as ice-free conditions. According to this classification, the stations in the West Spitsbergen Current (' $\mathrm{HG}$ '; seafloor depths $\sim 2500 \mathrm{~m}$ ) were seasonally ice-free stations, as the majority of the productive season in 2016 (March - July) they had no sea-ice (Fig. 1a; Table 1). On the other hand, in the East Greenland Current ('EG'; seafloor depth: 1000-2700 m) and the northern ('N'; 2500-2800 m) stations, sea-ice was present during most of the productive season, and these sites were thus defined as ice-covered stations (Fig. 1a; Table 1). Long-term sediment trap collections of particulate organic carbon (POC) fluxes at $200 \mathrm{~m}$ depth in the seasonally ice-free HG4 station have shown that the POC flux peaks early in the season due to ice-associated carbon export and again later in the season during the ice-free period due to POC export of pelagic production ${ }^{29}$. The POC export during the iceassociated flux peak (February to April) between 2001 and 2013 showed an inverse relationship between POC flux and distance to the ice-edge within $0-80 \mathrm{~km}$, i.e. the zone most influenced by melt water $\left(\mathrm{R}^{2}=0.39, p<0.01\right.$; Fig. $\left.1 \mathrm{~b}\right)$. This suggests that sea ice proximity can enhance POC fluxes. When the ice edge was beyond $80 \mathrm{~km}$ from the sediment traps, we observed no spatial effects between sea ice and POC export. To further test the hypotheses of sea-ice effects on carbon export efficiency, we assessed the exported organic matter and the vertical microbial connectivity at stations with contrasting ice-conditions in the Fram Strait during summer 2016. 
First we used a Lagrangian Particle Tracking algorithm based on the observed aggregate sinking 122 velocities (Table 1), to test whether our spatial classification scheme permitted the differentiation of particle origins. It showed less horizontal transport in the ice-covered regions compared to the icefree regions (Supplementary Fig. 1), and differences in the origin of the particles. Particles in the icefree region ('HG' stations) were primarily from the Atlantic waters south of the investigated region, and the majority of aggregates $(82 \%)$ reaching the deep ocean $(>1000 \mathrm{~m})$ and seafloor originated from ice-free surface waters (Supplementary Fig. 1). In the ice-covered region ('EG' and ' $N$ ' stations) below $1000 \mathrm{~m}$, a $60 \%$ of the aggregates originated from the ice-covered surface waters

129 (Table 1).

All sampled stations were at the later stage of the phytoplankton bloom, based on the rate of consumed nitrate, silica and phosphate above the seasonal pycnocline $(50 \mathrm{~m}$ depth, Supplementary Table 1). Microscopic analyses of water samples revealed that phyto- and protozooplankton communities in the chlorophyll $a$ maximum $(10-28 \mathrm{~m}$ depth) in the ice-free regions were dominated by Phaeocystis spp., heterotrophic dinoflagellates and ciliates, while the ice-covered regions were dominated by planktonic diatoms and Phaeocystis spp. (Supplementary Table 1). This was reflected in the composition of in situ formed aggregates collected using a marine snow catcher (MSC) directly below the chlorophyll a maximum (60 m depth), where Phaeocystis spp. dominated aggregates of the ice-free region and planktonic diatoms those of the ice-covered regions (Fig. 2). The aggregates from the ice-covered regions were two-fold larger (Wilcoxon Signed-Ranks Test; $p<0.01$; Table 2) and sank two-fold faster than the aggregates collected in the ice-free regions (Wilcoxon Signed-Rank Test; $p<0.01$; Table 2). Half of the aggregates collected in the ice-free region (13 out of 24) were smaller than $512 \mu \mathrm{m}$ in diameter, while almost all (33 out of 36) collected aggregates in the ice-covered regions were larger than $512 \mu \mathrm{m}$ (Fig. 2).

In addition, drifting sediment traps were equipped with a viscous gel to capture and preserve the size and structure of intact settling aggregates. The gel traps confirmed the MSC observations of Phaeocystis spp. dominated aggregates in the ice-free regions and planktonic diatom-dominated aggregates in the ice-covered regions. The gel traps showed similar numbers of particles exported in the ice-free and ice-covered regions, but confirmed that the aggregates in the ice-covered regions had on average two-fold larger diameters than those collected in the ice-free regions (Wilcoxon SignedRanks Test; $p<0.01$; Table 2). The larger diameters in the ice-covered regions translated into an order of magnitude larger average volume compared to aggregates of the ice-free regions (Table 2). Hence, in the period assessed in early summer, larger and faster-settling aggregates in the ice-covered regions caused a two-fold higher carbon export compared to the ice-free regions (Table 2). The carbon to nitrogen ratios $(\mathrm{C}: \mathrm{N}, \mathrm{mol}: \mathrm{mol})$ were 11 in the ice-free regions and 8 in the ice-covered regions, indicating export of fresher material from under the ice (Table 2). Furthermore, at the icestations macroscopic strands of the sea-ice diatom Melosira arctica were observed by sea ice sampling (Fig. 2e), as well as during high-resolution imaging of the seafloor in the ice-covered stations (doi:10.1594/PANGAEA.873926).

\section{Free-living and particle-associated microbial communities}

160 For both regions, free-living (FL) and particle-associated (PA) microbial communities of four distinct above the seafloor), were characterized using Illumina $16 \mathrm{~S}$ rRNA gene sequencing. For the analyses of the microbial community composition we chose amplicon sequence variants (ASVs) as the highest possible taxonomic resolution the method provides ${ }^{30}$. The final dataset consisted of 3,709,676 sequences from 66 samples that were assigned to 6,253 ASVs associated with bacterial and archaeal 
lineages (Supplementary Table 2). Rarefaction curves did not reach a plateau in any of the sampled communities, however, estimated asymptotic extrapolation to double amount of sequences showed only few additional ASVs (Supplementary Figure 2). Thus, our sequencing depth was satisfactory to represent most of the bacterial and archaeal diversity in all sampled microbial communities ${ }^{31}$. The classes Alphaproteobacteria, Bacteroidia and Gammaproteobacteria dominated the microbial communities in both FL and PA fractions, with no differences between ice-free and ice-covered regions (Supplementary Fig. 3). Each of these classes comprised more than $15 \%$ of the sequences and more than $10 \%$ of the ASVs in the entire dataset (Supplementary Fig. 3). In the deep ocean communities $(>1000 \mathrm{~m})$ there was an increasing abundance of the clades SAR202 (class Dehalococcoidia), SAR324 (Marine group B), SAR406 (Marinimicrobia), and the archaeal class Nitrososphaeria, each comprising 1-6\% of the sequences and 3-6\% of the ASVs in the entire dataset (Supplementary Fig. 3).

With increasing depth in the water column, microbial communities showed an increase in both richness (based on Chao1 richness estimator; Kruskal-Wallis test; Chi square $=37.24, \mathrm{df}=3, p<0.01$ ), and beta-diversity (based on Shannon's diversity index; Kruskal-Wallis test; Chi square=39.89, $\mathrm{df}=3$, $p<0.01$; Supplementary Fig. 4). In the FL communities, this trend was mostly caused by significant differences between the communities of surface and epipelagic, and epipelagic to mesoplagic layers (post-hoc Wilcoxon Signed-Ranks Test; $p$-adjusted<0.01). In contrast, in the PA communities the richness did not show significant changes from surface to epipelagic, and from epipelagic to mesoplagic layers, but significantly increased between meso- and bathypelagic layers (post-hoc Wilcoxon Signed-Ranks Test; $p$-adjusted $<0.01$ ). The beta-diversity of the PA communities did not change in the upper $100 \mathrm{~m}$ of the water column (i.e., from surface to epipelagic waters), but significantly increased with depth below the epipelagic layer (post-hoc Wilcoxon Signed-Ranks Test; p-adjusted<0.01; Supplementary Fig. 4).

The composition of microbial communities showed clear separation between the FL and PA communities (PERMANOVA test; $F_{1,64}=10.14, \mathrm{R}^{2}=0.09, p<0.01$ ). In both fractions the communities showed a specific clustering with the four distinct water layers (Fig. 3; PERMANOVA test; $\left.F_{3,64}=10.11, \mathrm{R}^{2}=0.30, p<0.01\right)$. Compared to the surface water-originating FL and PA communities, the dissimilarity between deeper FL and PA communities increased with depth (Kruskal-Wallis test; Chi square $=54.94, \mathrm{df}=7, p<0.01)$. There was no difference in depth-related dissimilarity of FL communities between ice-free and ice-covered regions (Fig. 3; Wilcoxon Signed-Ranks Test; $p>0.01$ ). However, in the PA fraction the communities of the ice-free region had significantly higher dissimilarity along the water column, compared to the PA communities of the ice-covered region (Fig. 3; Wilcoxon Signed-Ranks Test; $p<0.01$ ).

\section{Vertical connectivity and shifts in particle-associated communities}

Many free-living microbes are adapted to colonize particles in the water column. Thus, the observed vertical dissimilarity pattern of the PA communities could be associated with the changing diversity of the FL communities. In order to test this hypothesis and to estimate the extent of colonization, we applied a microbial source tracking (MST) Bayesian algorithm 'SourceTracker'. This MST approach assumes that ASVs diversity in various 'source' (i.e. FL) and corresponding 'sink' (i.e. PA) communities allows identification of statistically probable links between them (for detailed explanation see Methods section). The MST analysis showed a strong effect of the surface and epipelagic FL microbes on the composition of PA communities along the entire water column (Fig. 4). Within the surface and epipelagic layers, a particularly high proportion $(84 \pm 5 \%)$ of the PA

210 communities was associated with surface and epipelagic FL communities. In contrast, at meso- and 
211 bathypelagic depths the PA communities showed only a weak link to meso- and bathypelagic FL

212 communities (ca. 2 and $8 \%$ of the communities, respectively), and a large fraction (72 $\pm 5 \%$ ) was not

213 linked to any FL community. However, at meso- and bathypelagic depths, $27 \pm 6 \%$ of the PA

214 communities in ice-covered and $11 \pm 2 \%$ of PA communities in ice-free regions were linked to surface

215 and epipelagic FL communities (Fig. 4; Supplementary Table 3).

216 By statistical tests of comparative sequence enrichment, we identified the microbial taxonomic

217

218

219

220

221

222

223

224

225

226

227

228

229

230

231

232 groups that became significantly more abundant on sinking particles as a function of depth. The ASVs within the PA communities were defined as enriched when they had a $\log _{2}$ fold change of absolute value higher than 1 (i.e., double the amount of sequences) and an adjusted $p$ value lower than 0.1 (Fig. 5). This test looked at consecutive pelagic layers: surface-epipelagic, epipelagicmesopelagic and mesopelagic-bathypelagic. In both ice-free and ice-covered regions PA communities became enriched with increasing depth in the classes Gammaproteobacteria (with 40 and 18 enriched ASVs, respectively), Planctomycetes (with 37 and 27 enriched ASVs, respectively), Bacteroidia (43 and 8 enriched ASVs, respectively), and the poorly characterized class OM190 (with 34 and 19 enriched ASVs, respectively). The enriched ASVs of these classes reached up to 5\% of the sequences in the PA communities of the ice-covered regions and up to $10 \%$ of the sequences in the ice-free region. However, while the enriched ASVs of the classes Gammaproteobacteria and Bacteroidia were present also in the FL communities, the enriched ASVs of the classes Planctomycetes and OM190 were absent from the FL fraction ( $<0.5 \%$ of the sequences). Overall, we observed larger changes with depth in the PA communities of the ice-free region (where sinking speed was lower), resulting in more than double the amount of PA-enriched ASVs, in comparison to the ice-covered regions (348 and 158 ASVs, respectively; Supplementary Table 4).

\section{Transport of surface water-originating microbes to the bathypelagic: water column vs. seafloor}

Some of the vertically PA-enriched ASVs were also present in the FL communities along the water column (Fig. 6). In the bathypelagic, the PA-enriched ASVs comprised $17 \pm 2 \%$ of the sequences in the FL communities of the ice-covered region, and $47 \pm 4 \%$ of the sequences in the FL communities of the ice-free region. The most abundant family that consisted of such ASVs was the archaeal family Nitrosopumilacea, which comprised 3-4\% and 6-19\% of sequences in FL communities of the icecovered and ice-free regions, respectively.

The seeding of the deep-sea sediment by microbes on sinking particles was tested using 7 deep-sea sediment samples (uppermost centimeter) collected at the same stations as the water column communities across the Fram Strait. This dataset consisted of 1,209,785 sequences that were assigned to 11,145 ASVs associated with bacterial and archaeal lineages (Supplementary Table S2; Supplementary Fig. S2). The sediment microbial communities were mainly affiliated to the classes Alphaproteobacteria, Gammaproteobacteria, and Nitrososphaeria (Supplementary Fig. S3).

The vertically PA-enriched ASVs were also identified in the deep-sea sediment communities of both ice-covered and ice-free regions. These shared ASVs between the PA and the sediment communities were associated mainly with the archaeal family Nitrosopumilaceae (17 ASVs) and the bacterial family Woeseiaceae (8 ASVs; class Gammaproteobacteria), each comprised ca. 2-4\% of the sequences in the sediment communities (Fig. 6). Interestingly, in contrast to the PA-enriched ASVs of the family Nitrosopumilaceae that were also abundant in the FL communities of the bathypelagic, the shared ASVs of the family Woeseiaceae were absent from the FL communities $(<0.3 \%$ of sequences in all FL communities). Overall, in the ice-free region, 31\% of the PA-enriched ASVs were present in the sediment and comprised ca. $17 \%$ of the sequences in the sediment communities. 
255 In contrast, in the ice-covered regions $39 \%$ of the PA-enriched ASVs were present in the sediment

256 and comprised ca. $11 \%$ of the sequences in the sediment communities (Fig. 6).

\section{Discussion}

258 Throughout the world's oceans, settling particles export organic matter and nutrients, as well as of sea-ice on the dynamics on the composition and sinking velocities of settling particles and hence on export flux and efficiency in the Arctic. This is due to difficulties with the exchange of sediment traps and appropriate year-round upper ocean observations in ice-covered regions, limiting microbiological and biogeochemical deep-sea studies in the Arctic Ocean ${ }^{32,33}$. From what is known, snow and ice cover affect productivity by light limitation, and thereby carbon export is relatively low under the ice ${ }^{29,34}$. However, recently, the ice cover thinned substantially, so that it has lesser effect on light limitation and rafting of particles in the Central Arctic basins and in the Fram Strait ${ }^{27,28}$. Furthermore, it was found that the ice-margin can have stimulating effects on primary production early in the season, by meltwater-induced stratification and through seeding with ice-associated primary producers ${ }^{18,35}$. Spatially and temporarily this can lead to higher export efficiencies and stronger pelagobenthic coupling in regions with seasonal presence of the ice-margin, or covered partially by thinning sea-ice, including in the Fram Strait ${ }^{36}$, in the regions north of Svalbard ${ }^{37}$, as well as in the Central Arctic ${ }^{16}$.

273 Here, we studied the role of sea ice on settling particle characteristics and vertical microbial connectivity, and postulate links to carbon export efficiency in the Fram Strait. Our long-term assessment of the role of ice-coverage on particle export during periods with sea ice near the HG4 station suggested an important function of sea ice-distance on export fluxes early in spring during the ice-influenced phytoplankton bloom period. This encouraged us to assess the underlying principles of this connection between ice-associated export and the fate of microbial communities attached to particles close to the ice margin. At the time of sampling in June-July 2016, the late stage of the ongoing phytoplankton bloom was dominated by diatoms in the ice-covered region while in the adjacent ice-free region it was dominated by Phaeocystis spp. To test how ice-coverage impacts vertical connectivity and export of organic matter, we compared characteristics of sinking marine aggregates from ice-covered and ice-free regions of the Fram Strait during the productive period. In the ice-covered region we found larger diatom aggregates, with two-fold higher size-specific sinking velocities compared to the smaller Phaeocystis spp. aggregates that dominated ice-free regions. This caused almost two-fold higher carbon export rates under the ice, compared to adjacent ice-free waters during the same period. The long-term record in the Fram Strait also shows that annual particle flux is lower during warm water phases with less ice $^{38}$, and characterized by a shift from diatom to coccolithophorid and Phaeocystis spp. dominated phytoplankton during summertime at HG4 station $^{39}$. This is similar to observations north of Svalbard where ice-associated diatom production resulted in higher export than that observed for ice-free regions dominated by Phaeocystis spp. ${ }^{37}$. Taken together, this suggests that in the early Arctic summer, fast settling diatom aggregates drive export in ice-covered regions, whereas in warming, Atlantic-water influenced regions, the slower settling Phaeocystis spp. aggregates dominate and will lead to more pelagic recycling. In this study, this also affected carbon to nitrogen ratios of the sinking matter, which were lower for the settling particles collected by the drifting traps in the ice-covered regions compared to the ice-free regions of the Fram Strait (Table 1). Hence, a potential future shift to Atlantification of the Eurasian Arctic basins $^{40}$, with larger areas of thermally stratified open waters, flagellate-dominated phytoplankton blooms, slower settling aggregates and stronger grazing pressure may lead to higher degradation and 
transformation of organic matter during its journey through the water column, thus, resulting in lower amounts and less labile organic matter reaching the seafloor.

302 In this study we tested, for the first time in Arctic deep waters, the previously established hypothesis that vertical microbial connectivity is stronger in ecosystems dominated by fast-settling aggregates $^{22,23}$, due to the shorter transit time through the water column. In both ice-covered and icefree regions of the Fram Strait, free-living (FL) pelagic microbial communities from different depths had greater dissimilarities to each other than the particle-associated (PA) communities from the same depths. This suggests a stratified water column with distinct microbial communities in the different water layers, as well as a vertical dispersal of microbial communities between surface ocean and deep-sea via sinking particles. In this context, settling particles are not only important for the export of organic matter to the deep ocean, but they also promote microbial heterotrophic activity and seeding $^{22,23,33}$, and thereby shape microbial biogeography and biogeochemical functioning in mesoand bathypelagic realms.

313 The surface water-originating microbial families that were significantly enriched on particles collected at depth, such as various members of the class Bacteroidia, are associated with phytoplankton blooms in the region ${ }^{32,41}$, and are known to be highly active organic matter degraders ${ }^{42}$. Furthermore, it has recently been shown that there is a dominance of enzymatic activity phylogenetically linked to these taxonomic groups in the bathypelagic ${ }^{43}$ and that this enzymatic activity is predominantly linked to a particle-associated lifestyles ${ }^{44}$. This indicates that active microbes originating from surface waters and associated with sinking particles continue to process organic matter while they sink to the deep ocean, and thus may remain key players in the biogeochemical cycling in the deep ocean. The cold water-adapted (i.e., psychrophilic) microbes of polar waters may potentially thrive in the deep Arctic ocean characterized by a relatively uniform temperature. Our results show that almost half of the bathypelagic FL communities consisted of vertically PA-enriched ASVs. This suggests that surface water-originating microbes may realize an ecological niche in bathypelagic waters. Evidence for this is provided by the archaeal family Nitrosopumilaceae, which was the most abundant among taxonomic groups with PA-enriched ASVs in bathypelagic FL communities. Previous analyses showed that epipelagic and bathypelagic members of this family are phylogenetically closer to each other than those found in the intermediate mesopelagic waters ${ }^{45}$. Based on our results, this pattern may be explained by a niche realization in the bathypelagic of Nitrosopumilaceae family members exported from the surface ocean on sinking particles.

In both ice-free and adjacent ice-covered regions, the high similarity between surface PA and FL communities suggested that particles were colonized in surface waters, similar to other oceanic regions ${ }^{22,23,25,26}$. Even in the bathypelagic, a substantial proportion of the PA community was still comprised of microbes recruited in the surface ocean. Notably, particles in the meso- and bathypelagic contained a high proportion of sequences that were not linked to the FL community at any depth, indicating a shift in population densities in the particle, e.g. by growth of otherwise rare types in the particles. Alternatively, the relatively long sinking time of days to weeks could have led to PA microbial communities at depth containing an imprint of surface water's microbial communities that were no longer present or horizontally offset during our sampling. Overall, we conclude from our data that the observed vertical changes in the PA communities are substantially affected by sinking speed, causing different encounter rates and colonization in the surface ocean ${ }^{46}$, and differences in time for ecological succession within the particles ${ }^{47}$. The succession can result from transformations in the aggregate composition during aging and turnover ${ }^{48}$, grazing by protozoans $^{49}$, viral infection ${ }^{50}$, or changing environmental conditions, such as increasing hydrostatic 
pressure $^{51,52}$. Common to all these processes is that slower sinking will enhance selection of some taxonomic groups and lead to the demise of others, potentially allowing rare taxa to become abundant at depth while those that were abundant at shallower depths become rarer. Furthermore, a large fraction of sinking particles remains suspended in the bathypelagic ${ }^{53}$. In this way, settling aggregates should be viewed as constantly changing microcosms that have some exchange with their surroundings in the deep ocean ${ }^{26}$, but where particle sinking speed is an important driver of succession. In Arctic waters, it seems that fast aggregate sinking speed is strongly related to ecological impact from sea-ice cover.

Since the seafloor is the final destination for those particles that make the journey through the water column, we tested whether the vertical microbial connectivity extends to deep-sea sediment. We found that ca. $10-20 \%$ of the sequences in the deep-sea sediment were related to PA-enriched microbes originating from the surface waters and deposited via sinking particles, in both ice-covered and ice-free regions. These results are comparable to observations in the Central Arctic Ocean after deposition of ice algae on the deep seafloor ${ }^{33}$, and are higher than the global average of $<10 \%{ }^{54}$. Interestingly, the family Woeseiaceae (class Gammaproteobacteria) showed the strongest benthicpelagic connectivity via sinking particles, indicating its export from surface to bathypelagic waters via sinking particles ${ }^{22}$. Recent genomic characterization of this largely unknown taxonomic group (which was conducted using sediment samples collected in the Fram Strait) suggests their involvement in the cycling of detrital proteins in marine benthic environments ${ }^{55}$. Using targeted fluorescence microscopy of the total pelagic microbial communities (based on samples collected in parallel to this study), Hoffmann et al. (2020) also showed, that cells of this taxonomic group were present throughout the entire water column, comprising $<1 \%$ of the community. We found that pelagic members of the Woeseiaceae were associated with sinking particles, but not free-living, suggesting that this important benthic heterotroph is one of the few types of bacteria that cover all water depths by a particle-associated life style.

In conclusion, our study supports the notion that sea-ice retreat can have an important ecological impact on carbon flux characteristics, and on long term potentially affect the deep-ocean microbial diversity. Fast settling ice-associated diatom aggregates drive higher export efficiency and cause stronger pelagic-benthic coupling including the transport of functionally important microbial groups, whereas slow settling Phaeocystis spp. aggregates associated with seasonally ice-free regions may lead to more pelagic recycling and less connectivity. These changes may substantially alter deep water and seafloor communities in the Arctic.

\section{Methods}

\section{Water sampling and metadata collection}

380 The sampling was performed during RV Polarstern expedition PS99.2 to the LTER observatory HAUSGARTEN in the Fram Strait (June $24^{\text {th }}-$ July $16^{\text {th }}$ 2016). Water samples were collected using

$38212 \mathrm{~L}$ Niskin bottles mounted on a CTD rosette (Sea-Bird Electronics Inc. SBE 911 plus probe) equipped with double temperature and conductivity sensors, a pressure sensor, chlorophyll $a$ fluorometer, and transmissometer. At all stations water samples were collected from surface at 10-30 $\mathrm{m}, 100 \mathrm{~m}, 1000 \mathrm{~m}$ and $\sim 50 \mathrm{~m}$ above the seafloor (Supplementary Table S2). For assessing archaeal and bacterial community composition, $4 \mathrm{~L}$ in epipelagic $(<100 \mathrm{~m})$ and $8-12 \mathrm{~L}$ in meso- and bathypelagic waters were filtered with a peristaltic pump (Masterflex; Cole Parmer) through successive membrane filters of $5 \mu \mathrm{m}$ (Whatman Nucleopore, $47 \mathrm{~mm}$ polycarbonate), and $0.22 \mu \mathrm{m}$ (Millipore Sterivex ${ }^{\mathrm{TM}}$ filters). In addition, deep-sea sediment cores were collected with a TV-guided 
multicorer, and subsamples of the uppermost centimeter of the cores were collected with syringes (Supplementary Table S2). All samples were stored at $-20{ }^{\circ} \mathrm{C}$ until DNA isolation.

392 Hydrographic data of the seawater including temperature and salinity 393 (doi:10.1594/PANGAEA.871952), as well as the inorganic nutrient concentrations 394 (doi:10.1594/PANGAEA.906132) were retrieved from PANGAEA. The map in Fig. 1a was generated using ArcMap (v10.5) with Esri world countries dataset (www.esri.com) in a WGS 1984 Arctic Polar Stereographic map projection. The mean monthly sea-ice concentrations for Fig. 1a were retrieved from http://data.seaiceportal.de ${ }^{56}$, and sea surface temperature was obtained from NOAA NCEP real-time analysis (http://polar.ncep.noaa.gov/sst/rtg_high_res/).

\section{Long-term sediment trap deployment and sea-ice distance estimation}

400 The long-term moored KIEL sediment trap (sampling area $0.5 \mathrm{~m}^{2}$ and 20 collection cups) was station (HG4 - $79.01^{\circ} \mathrm{N}, 4.20^{\circ} \mathrm{E}$; Fig. 1). The deployment depths of the sediment trap was $\sim 200 \mathrm{~m}$. Sampling cups were filled with filtered seawater adjusted to a salinity of 40 and fixed with $0.14 \%$ final solution of $\mathrm{HgCl}_{2}$. The opening time of the sampling cups varied between 7 and 59 days, depending on the season with short opening time during the polar day and long opening time during the polar night. Swimmers were removed after recovery and triplicate subsamples were measured for particulate organic carbon (POC) by filtering the material onto pre-combusted Whatman GF/F filters, soaking them in $0.1 \mathrm{~N} \mathrm{HCl}$, and drying at $60^{\circ} \mathrm{C}$ before analyzing with a $\mathrm{CHN}$ elemental analyzer ${ }^{14,36}$. The data was retrieved from PANGAEA (doi: 10.1594/PANGAEA.855473).

To evaluate the impact of the sea ice concentration on the POC flux during periods when peak POC flux was associated with sea ice (February to April), we used POC flux collected by the long-term sediment trap of the central station HG4. The daily distance between the sea-ice edge and HG4 was estimated using daily sea-ice concentration satellite images from NSIDC/NOAA (http://nsidc.org/data/nsidc-0051). The images were generated using the NASA Team algorithm ${ }^{57}$ and mapped to a $25 \times 25 \mathrm{~km}$ grid. This satellite data set was derived from brightness and temperature data generated from Scanning Multichannel Microwave Radiometer and Sensor Microwave Imager and Sounder equipped on the Nimbus-7 satellite and the Defence Meteorological Satellite Program, respectively. The distance to the ice-edge was defined at the position with $15 \%$ sea-ice concentration. The ice-edge nearest the HG4 position was used to calculate the daily ice-distance and averaged for each opening time of the collection cups ( 14 days) on the long-term moored sediment traps.

\section{Microscopic analysis of phyto- and protozooplankton}

The plankton community composition at the chlorophyll $a$ maximum was identified and the phytoplankton abundance was counted using light microscopy. Seawater samples were preserved in hexamethylenetetramine-buffered formalin (final concentration 0.5-1\%) and stored in brown glass bottles. For microscopic analyses an aliquot of $50 \mathrm{~mL}$ was transferred to Utermöhl settling chambers where the cells were allowed to settle for 48 hours. At least 500 cells of the dominant phytoplankton species or groups were counted with an inverted microscope at three different magnifications using phase contrast according to Utermöhl (1958) and Edler (1979). 
431 Using a marine snow catcher (MSC, OSIL, United Kingdom) we sampled intact aggregates from 60 $\mathrm{m}$ at ice-free and ice-covered regions, and measured their size, composition, and sinking velocities. The aggregates were individually transferred to a vertical flow chamber ${ }^{58}$ filled with Whatman GF/F filtered seawater collected from the same MSC and kept at in situ temperature. The $\mathrm{x}-, \mathrm{y}-$, and $\mathrm{z}$-axes of each aggregate were measured in the vertical flow system using a horizontal dissection microscope and an ocular with a scale. The aggregate volume was thereafter calculated assuming an ellipsoidal shape and the equivalent spherical diameter (ESD) was calculated from the aggregate's volume. The sinking velocity was measured by increasing the upward flow in the flow-chamber until the aggregate was floating one diameter above the net. The sinking velocity was thereafter calculated by determining the volumetric flow rate three times, and dividing the average of these measurements by the area of the flow chamber. The composition of the aggregates was determined with an inverted light microscope using Utermöhl chambers (Fig. 2).

\section{Aggregate and carbon export to $100 \mathrm{~m}$}

Aggregate and carbon export to $100 \mathrm{~m}$ depth was measured using the free-drifting surface-tethered sediment traps in the ice-free and ice-covered regions ${ }^{26}$. The drifting traps consisted of a drifting array attached to a surface buoy equipped with a GPS satellite transmitter, two surface floats and 12 small buoyancy balls that served as wave breakers to reduce hydrodynamic mixing effects on the sediment traps. The $100 \mathrm{~m}$ collection depth was equipped with four gimbal-mounted cylinders, each $1 \mathrm{~m}$ tall and $10.4 \mathrm{~cm}$ in inner diameter. Three of the cylinders collected samples for biogeochemical measurements and the last collection cylinder contained $200 \mathrm{ml}$ of a viscous gel, which intercepted and preserved settling particles without destroying their original sizes and structures. Upon recovery, the material collected for biogeochemical fluxes was fixed with $\mathrm{HgCl}_{2}$ and stored at $4{ }^{\circ} \mathrm{C}$ until further analyses in the home laboratory. The particles collected in the gels were photographed using a stereo microscope equipped with a 3.1 megapixel digital camera and a $105 \mathrm{~mm}$ macro lens, resulting in a pixel size of $12 \mu \mathrm{m}$. The image analyses were performed with a routine written in MATLAB (The MathWorks) using the image analysis toolbox. Each image was converted into grey scale and the background was removed by applying a threshold value. The calibrated pixel area $\left(\mathrm{mm}^{2}\right)$ in each projected particle was converted into the equivalent spherical diameter (ESD).

\section{DNA isolation and 16S rRNA amplicon sequencing}

Genomic bacterial and archaeal DNA was isolated from size-fractionated filtration through $5 \mu \mathrm{m}$ and $0.22 \mu \mathrm{m}$ filters membranes to analyze the particle-associated (PA, $>5 \mu \mathrm{m}$ ) and the free-living (FL, $>0.22 \mu \mathrm{m}$ and $<5 \mu \mathrm{m})$ community. The isolations were conducted by a combined chemical and mechanical procedure using the PowerWater DNA Isolation Kit, and PowerSoil DNA Isolation Kit for the sediment samples (MO BIO Laboratories, Inc., Carlsbad, CA, USA). Prior to DNA isolation the Sterivex ${ }^{\mathrm{TM}}$ cartridges of the $0.22 \mu \mathrm{m}$ membranes were opened in order to place the filters in the kit-supplied bead beating tubes. The isolation was continued according to the manufacturer's instructions, and DNA was stored at $-20{ }^{\circ} \mathrm{C}$. Library preparation was performed according to the standard instructions of the 16S Metagenomic Sequencing Library Preparation protocol (Illumina, Inc., San Diego, CA, USA). The hyper variable V4-V5 region of the 16S rRNA gene was amplified using bacterial primers 515F-Y (5'-GTGYCAGCMGCCGCGGTAA-3') and 926R (5'CCGYCAATTYMTTTRAGTTT-3 $)^{59}$. Sequences were obtained on the Illumina MiSeq platform in a $2 \times 300$ bp paired-end run (CeBiTec Bielefeld, Germany), following the standard instructions of the 16S Metagenomic Sequencing Library Preparation protocol (Illumina, Inc., San Diego, CA, USA). 
475 under accession number PRJEB30254. The data were archived using the brokerage service of the 476 German Federation for Biological Data (GFBio) ${ }^{61}$.

\section{Bioinformatics and statistical analyses}

478 The raw paired-end reads were primer-trimmed using cutadapt ${ }^{62}$. Further analyses were conducted

479 using R (v3.6.3; http:/www.Rproject.org/) in RStudio (v1.2.5033; http://www.rstudio.com/). The 480 trimmed libraries were processed using DADA2 (v1.14.1) ${ }^{30}$, following the suggested tutorial 481 (https://benjjneb.github.io/dada2/tutorial.html). Briefly, chimeras and singletons were filtered out. 482 The produced amplicon sequence variants (ASVs) were taxonomically classified against the Silva 483 reference database (release 138) ${ }^{63}$. The ASVs that were taxonomically unclassified on domain level, 484 or not assigned to bacterial or archaeal lineages, were excluded from further analysis. Furthermore, 485 all ASVs which were taxonomically assigned to mitochondria and chloroplast were removed from 486 the dataset.

Sample data matrices were managed using the R package 'phyloseq' (v1.28.0) ${ }^{64}$ and plots were generated using R package 'ggplot2' (v3.3.0) ${ }^{65}$. The sample rarefaction analyses were conducted using R package 'iNEXT' (v2.0.20) ${ }^{31}$. Prior to beta-diversity analyses, a prevalence threshold (i.e., in how many samples did an ASV appear at least once) of 4\% was applied on the ASV abundance table. Principal component analysis (PCA) and dissimilarity comparisons between FL and PA communities were conducted on a stabilized ASV abundance table based on the geometric mean. The fold-change in abundance of each ASV between the water layers was calculated using the R package 'DEseq2' $(\mathrm{v} 1.24 .0)^{66}$. The method applies a generalized exact binomial test on variance stabilized ASV abundance.

496 Based on the assumption that the particle-associated microbial communities (i.e., 'sink' communities) are the result of various events of colonization of marine aggregates by free-living microbes (i.e., 'source' communities); a Bayesian microbial source tracking algorithm 'SourceTracker' (v1.0) ${ }^{67}$ was applied on the ASV abundance table. The algorithm performance was validated using a 'leave-one-out' approach, in which each 'source' (i.e., FL) community was hidden, in turn, from the training dataset, and its origin was predicted based on the rest of the source samples in the dataset. The entire analysis was conducted under default conditions: burn-in period - 100, restarts - 10, dirichlet hyperparameters $(\alpha, \beta)-0.001$. All samples were randomly sub-sampled to 5,000 sequences. Scripts for the molecular data processing and statistical analyses can be accessed at https://github.com/edfadeev/Vertical_connectivity_Arctic_Ocean.

\section{Modeled aggregates sinking trajectories}

A Lagrangian particle tracking algorithm was used to back-track particles from the sampling depth to the surface. A detailed description of the model can be found Wekerle et al, $2018^{68}$. Briefly, the backward particle computation is done by reversing the flow field, i.e. particles are treated as if they were rising from the sampling depth to the surface with a negative sinking speed, being horizontally displaced with the reversed horizontal velocity. Particles were advected with daily averaged 3D model velocities from the ocean general circulation model FESOM (an ocean-sea ice model based on unstructured meshes $)^{69}$. The particle sinking speed was computed by adding a constant sinking speed to the modelled vertical velocity. In this study, we used a FESOM configuration optimized for the Fram Strait, applying a mesh resolution of $1 \mathrm{~km}^{70}$. The performance of the model was validated for 
The backward trajectory calculation was performed for all three sampled regions (ice-free ' $\mathrm{HG}$ '

518 stations, and ice-covered 'EG' and ' $\mathrm{N}$ ' stations), using on-board measurements of aggregate sinking velocities (Table 1). Trajectories were released around $300 \mathrm{~m}$ above the seafloor once per day during the year March - July 2016, however we restricted the analysis to particles that reached the ocean surface between March and July 2016. A time step of 30 min was used for the trajectory calculation, and bi-hourly positions and corresponding temperature and salinity values were stored. To quantify the vertical distribution of particles, their positions were binned into a grid with bin sizes of $25 \mathrm{~m}$ depth $\mathrm{x} 0.05^{\circ}$ Longitude/Latitude and then divided by the total number of particles to determine the fraction of particles originating from each grid box (Table 2). The daily concentrations of sea-ice were retrieved from Centre d'Exploitation et de Recherche SATellitaire (CERSAT; http://cersat.ifremer.fr/).

\section{Acknowledgments}

529 We thank the captain and crew of RV Polarstern expedition PS99.2 and the chief scientist Thomas 530 Soltwedel. Thanks to Josephine Z. Rapp for the sediment sampling, Lisa Zacharski for microscopy 531 counts of the phyto- and protozoolankton communities, Pierre Offre for assistance with the water 532 sampling, and Halina Tegetmeyer for sequencing of the samples. Furthermore, we thank Gerhard J. Herndl, Wilken-Jon von Appen, Daniel Sher, and Hannah Marchant for critical review of the manuscript. This work was conducted in the framework of the HGF Infrastructure Program FRAM of the Alfred-Wegener-Institute Helmholtz Center for Polar and Marine Research. The project has received funding from the European Research Council (ERC) under the European Union's Seventh Framework Programme (FP7/2007-2013) research project ABYSS (grant agreement no. 294757) to AB. Additional funding came from the Helmholtz Association specifically for the FRAM infrastructure, the Max Planck Society, the HGF Young Investigator Group SeaPump "Seasonal and regional food web interactions with the biological pump": VH-NG-1000 to MHI, the Austrian Science Fund (FWF): M 2797-B to EF, the Helmholtz Initiative and Networking Fund "The Polar System and its Effects on the Ocean Floor" to SR and MHI, as well asthe DFG-Research Center/Cluster of Excellence "The Ocean Floor - Earth's Uncharted Interface": EXC-2077390741603 to SR and MHI. This publication is Eprint ID 49364 of the Alfred Wegener Institute for Polar and Marine Research, Bremerhaven, Germany.

\section{Authors contribution}

$\mathrm{EF}$ analyzed the data and wrote the manuscript with guidance from $\mathrm{MHI}, \mathrm{AB}, \mathrm{CB}$ and IS. MHI conducted the aggregate characterization on board. SR conducted the long-term sediment traps analysis. AR and AMW contributed to sampling, and data analysis of an early version of the manuscript. EMN conducted the microscopic analysis of phyto- and protozooplankton and was responsible for POC flux analysis of long-term moorings. CW modeled the aggregates sinking trajectories. All authors contributed to the final version of the manuscript.

\section{Competing interests}

554 The authors declare no competing interests.

\section{References}

556 1. Serreze, M. C. \& Meier, W. N. The Arctic's sea ice cover: trends, variability, predictability, 557 and comparisons to the Antarctic. Ann. N. Y. Acad. Sci. 1436, 36-53 (2019). 
2. Pörtner, H. et al. IPCC, 2019: IPCC Special Report on the Ocean and Cryosphere in a Changing Climate. Intergov. Panel Clim. Chang. 1-765 (2019).

3. Kwok, R. Arctic sea ice thickness, volume, and multiyear ice coverage: losses and coupled variability (1958-2018). Environ. Res. Lett. 13, 105005 (2018).

4. Wassmann, P. \& Reigstad, M. Future Arctic Ocean seasonal ice zones and implications for pelagic-benthic coupling. Oceanography 24, 220-231 (2011).

5. Nöthig, E. M. et al. Summertime plankton ecology in fram strait-a compilation of long-and short-term observations. Polar Res. 34, 1-18 (2015).

6. Assmy, P. et al. Leads in Arctic pack ice enable early phytoplankton blooms below snowcovered sea ice. Sci. Rep. 7, 40850 (2017).

7. Neukermans, G., Oziel, L. \& Babin, M. Increased intrusion of warming Atlantic water leads to rapid expansion of temperate phytoplankton in the Arctic. Glob. Chang. Biol. 24, 2545-2553 (2018).

8. Wiedmann, I. et al. What Feeds the Benthos in the Arctic Basins? Assembling a Carbon Budget for the Deep Arctic Ocean. Front. Mar. Sci. 7, (2020).

9. Randelhoff, A. \& Sundfjord, A. Short commentary on marine productivity at Arctic shelf breaks: upwelling, advection and vertical mixing. Ocean Sci. 14, 293-300 (2018).

10. Lewis, K. M., van Dijken, G. L. \& Arrigo, K. R. Changes in phytoplankton concentration now drive increased Arctic Ocean primary production. Science (80-. ). 369, 198-202 (2020).

11. Arrigo, K. R. \& van Dijken, G. L. Continued increases in Arctic Ocean primary production. Prog. Oceanogr. 136, 60-70 (2015).

12. Leu, E. et al. Arctic spring awakening - Steering principles behind the phenology of vernal ice algal blooms. Prog. Oceanogr. 139, 151-170 (2015).

13. Arrigo, K. R. et al. Massive Phytoplankton Blooms Under Arctic Sea Ice. Science (80-. ). 336, 1408-1408 (2012).

14. Lalande, C. et al. Variability in under-ice export fluxes of biogenic matter in the Arctic Ocean. Global Biogeochem. Cycles 28, 571-583 (2014).

15. Fernández-Méndez, M. et al. Photosynthetic production in the central Arctic Ocean during the record sea-ice minimum in 2012. Biogeosciences 12, 3525-3549 (2015).

16. Boetius, A. et al. Export of Algal Biomass from the Melting Arctic Sea Ice. Science (80-. ). 339, 1430-1432 (2013).

17. Assmy, P. et al. Floating Ice-Algal Aggregates below Melting Arctic Sea Ice. PLoS One 8, e76599 (2013).

18. Perrette, M., Yool, A., Quartly, G. D. \& Popova, E. E. Near-ubiquity of ice-edge blooms in the Arctic. Biogeosciences 8, 515-524 (2011). 
19. Underwood, G. J. C. et al. Organic matter from Arctic sea-ice loss alters bacterial community structure and function. Nat. Clim. Chang. 9, 170-176 (2019).

20. Herndl, G. J. \& Reinthaler, T. Microbial control of the dark end of the biological pump. Nat. Geosci. 6, 718-724 (2013).

21. Henson, S., Le Moigne, F. \& Giering, S. Drivers of Carbon Export Efficiency in the Global Ocean. Global Biogeochem. Cycles 33, 891-903 (2019).

22. Ruiz-González, C. et al. Major imprint of surface plankton on deep ocean prokaryotic structure and activity. Mol. Ecol. mec.15454 (2020). doi:10.1111/mec.15454

23. Mestre, M. et al. Sinking particles promote vertical connectivity in the ocean microbiome. Proc. Natl. Acad. Sci. U. S. A. 115, E6799-E6807 (2018).

24. Preston, C. M., Durkin, C. A. \& Yamahara, K. M. DNA metabarcoding reveals organisms contributing to particulate matter flux to abyssal depths in the North East Pacific ocean. Deep Sea Res. Part II Top. Stud. Oceanogr. 173, 104708 (2020).

25. Boeuf, D. et al. Biological composition and microbial dynamics of sinking particulate organic matter at abyssal depths in the oligotrophic open ocean. Proc. Natl. Acad. Sci. U. S. A. 116, 11824-11832 (2019).

26. Thiele, S., Fuchs, B. M., Amann, R. \& Iversen, M. H. Colonization in the Photic Zone and Subsequent Changes during Sinking Determine Bacterial Community Composition in Marine Snow. Appl. Environ. Microbiol. 81, 1463-1471 (2015).

27. Smedsrud, L. H., Halvorsen, M. H., Stroeve, J. C., Zhang, R. \& Kloster, K. Fram Strait sea ice export variability and September Arctic sea ice extent over the last 80 years. Cryosphere 11, 65-79 (2017).

28. Krumpen, T. et al. Arctic warming interrupts the Transpolar Drift and affects long-range transport of sea ice and ice-rafted matter. Sci. Rep. 9, 5459 (2019).

29. Lalande, C. et al. Lateral supply and downward export of particulate matter from upper waters to the seafloor in the deep eastern Fram Strait. Deep Sea Res. Part I Oceanogr. Res. Pap. 114, 78-89 (2016).

30. Callahan, B. J. et al. DADA2: High-resolution sample inference from Illumina amplicon data. Nat. Methods 13, 581-583 (2016).

31. Hsieh, T. C., Ma, K. H. \& Chao, A. iNEXT: Interpolation and Extrapolation for Species Diversity. (2018).

32. Wilson, B. et al. Changes in marine prokaryote composition with season and depth over an Arctic polar year. Front. Mar. Sci. 4, 1-17 (2017).

33. Rapp, J. Z., Fernández-Méndez, M., Bienhold, C. \& Boetius, A. Effects of ice-algal aggregate export on the connectivity of bacterial communities in the central Arctic Ocean. Front. Microbiol. 9, (2018). 
34. Leu, E., Søreide, J. E., Hessen, D. O., Falk-Petersen, S. \& Berge, J. Consequences of changing sea-ice cover for primary and secondary producers in the European Arctic shelf seas: Timing, quantity, and quality. Prog. Oceanogr. 90, 18-32 (2011).

35. Becagli, S. et al. Relationships linking primary production, sea ice melting, and biogenic aerosol in the Arctic. Atmos. Environ. 136, 1-15 (2016).

36. Lalande, C., Bauerfeind, E., Nöthig, E. \& Beszczynska-möller, A. Impact of a warm anomaly on export fluxes of biogenic matter in the eastern Fram Strait. Prog. Oceanogr. 109, 70-77 (2013).

37. Olli, K. et al. Food Web Functions and Interactions During Spring and Summer in the Arctic Water Inflow Region: Investigated Through Inverse Modeling. Front. Mar. Sci. 6, (2019).

38. Bauerfeind, E. et al. Particle sedimentation patterns in the eastern Fram Strait during 2000 2005 : Results from the Arctic long-term observatory HAUSGARTEN. Deep Sea Res. Part I 56, 1471-1487 (2009).

39. Soltwedel, T. et al. Natural variability or anthropogenically-induced variation? Insights from 15 years of multidisciplinary observations at the arctic marine LTER site HAUSGARTEN. Ecol. Indic. 1-14 (2015). doi:10.1016/j.ecolind.2015.10.001

40. Polyakov, I. V. et al. Greater role for Atlantic inflows on sea-ice loss in the Eurasian Basin of the Arctic Ocean. Science (80-. ). 356, 285-291 (2017).

41. Fadeev, E. et al. Microbial Communities in the East and West Fram Strait During Sea Ice Melting Season. Front. Mar. Sci. 5, (2018).

42. Buchan, A., LeCleir, G. R., Gulvik, C. a., González, J. M. \& Gonzalez, J. M. Master recyclers: features and functions of bacteria associated with phytoplankton blooms. Nat. Rev. Microbiol. 12, 686-698 (2014).

43. Bergauer, K. et al. Organic matter processing by microbial communities throughout the Atlantic water column as revealed by metaproteomics. Proc. Natl. Acad. Sci. 115, E400-E408 (2018).

44. Zhao, Z., Baltar, F. \& Herndl, G. J. Linking extracellular enzymes to phylogeny indicates a predominantly particle-associated lifestyle of deep-sea prokaryotes. Sci. Adv. 6, 1-11 (2020).

45. Hatzenpichler, R. Diversity, Physiology, and Niche Differentiation of Ammonia-Oxidizing Archaea. Appl. Environ. Microbiol. 78, 7501-7510 (2012).

46. Słomka, J., Alcolombri, U., Secchi, E., Stocker, R. \& Fernandez, V. I. Encounter rates between bacteria and small sinking particles. New J. Phys. 22, 043016 (2020).

47. Datta, M. S., Sliwerska, E., Gore, J., Polz, M. F. \& Cordero, O. X. Microbial interactions lead to rapid micro-scale succesions on model marine particles. Nat. Commun. 7, 1-7 (2016).

48. Ploug, H., Iversen, M. H. \& Fischer, G. Ballast, sinking velocity, and apparent diffusivity within marine snow and zooplankton fecal pellets: Implications for substrate turnover by 
attached bacteria. Limnol. Oceanogr. 53, 1878-1886 (2008).

666

667

668

669

670

671

672

673

674

675

676

677

678

679

680

681

682

683

684

685

686

687

688

689

690

691

692

693

694

695

696

697

698

699

700

49. Kiørboe, T., Tang, K., Grossart, H. \& Ploug, H. Dynamics of Microbial Communities on Marine Snow Aggregates : Colonization, Growth, Detachment, and Grazing Mortality of Attached Bacteria. 69, 3036-3047 (2003).

50. Proctor, L. M. \& Fuhrman, J. A. Roles of viral infection in organic particle flux. Mar. Ecol. Prog. Ser. 69, 133-142 (1991).

51. Tamburini, C. et al. Effects of hydrostatic pressure on microbial alteration of sinking fecal pellets. Deep Sea Res. Part II Top. Stud. Oceanogr. 56, 1533-1546 (2009).

52. Grossart, H. P. \& Gust, G. Hydrostatic pressure affects physiology and community structure of marine bacteria during settling to $4000 \mathrm{~m}$ : An experimental approach. Mar. Ecol. Prog. Ser. 390, 97-104 (2009).

53. Bochdansky, A. B., Clouse, M. A. \& Herndl, G. J. Dragon kings of the deep sea: Marine particles deviate markedly from the common number-size spectrum. Sci. Rep. 6, 4-10 (2016).

54. Zinger, L., Boetius, A. \& Ramette, A. Bacterial taxa-area and distance-decay relationships in marine environments. Mol. Ecol. 23, 954-964 (2014).

55. Hoffmann, K. et al. Diversity and metabolism of Woeseiales bacteria, global members of marine sediment communities. ISME J. 14, 1042-1056 (2020).

56. Spreen, G., Kaleschke, L. \& Heygster, G. Sea ice remote sensing using AMSR-E 89-GHz channels. J. Geophys. Res. 113, C02S03 (2008).

57. Cavalieri, D. J., Parkinson, C. L., Gloersen, P. \& Zwally, H. J. Sea Ice Concentrations from Nimbus-7 SMMR and DMSP SSM/I-SSMIS Passive Microwave Data, Version 1. (1996). doi:https://doi.org/10.5067/8GQ8LZQVL0VL

58. Ploug, H. \& Jørgensen, B. B. A net-jet flow system for mass transfer and micro electrode studies in sinking aggregates. Mar. Ecol. Prog. Ser. 176, 279 (1999).

59. Parada, A. E., Needham, D. M. \& Fuhrman, J. A. Every base matters: Assessing small subunit rRNA primers for marine microbiomes with mock communities, time series and global field samples. Environ. Microbiol. 18, 1403-1414 (2016).

60. Silvester, N. et al. The European Nucleotide Archive in 2017. Nucleic Acids Res. 46, D36D40 (2018).

61. Diepenbroek, M. et al. Towards an integrated biodiversity and ecological research data management and archiving platform: the German federation for the curation of biological data (GFBio). in Informatik 2014 (eds. Plödereder, E., Grunske, L., Schneider, E. \& Ull, D.) 17111721 (Gesellschaft für Informatik e.V., 2014).

62. Martin, M. Cutadapt removes adapter sequences from high-throughput sequencing reads. EMBnet.journal 17, 10 (2011).

63. Quast, C. et al. The SILVA ribosomal RNA gene database project : improved data processing 
and web-based tools. 41, 590-596 (2013).

702

703

704

705

706

707

708

709

710

711

712

713

714

715

716

717
64. McMurdie, P. J. \& Holmes, S. phyloseq: An R Package for Reproducible Interactive Analysis and Graphics of Microbiome Census Data. PLoS One 8, e61217 (2013).

65. Gómez-Rubio, V. ggplot2 - Elegant Graphics for Data Analysis (2nd Edition). J. Stat. Softw. 77, (2017).

66. Love, M. I., Huber, W. \& Anders, S. Moderated estimation of fold change and dispersion for RNA-seq data with DESeq2. Genome Biol. 15, 550 (2014).

67. Knights, D. et al. Bayesian community-wide culture-independent microbial source tracking. Nat. Methods 8, 761-763 (2011).

68. Wekerle, C., Krumpen, T., Dinter, T., Iversen, M. \& Salter, I. Origin and properties of sediment trap catchment areas in Fram Strait : results from Lagrangian modelling and remote sensing. Front. Mar. Sci. 1-26 (2018). doi:10.3389/fmars.2018.00407

69. Wang, Q. et al. The Finite Element Sea Ice-Ocean Model (FESOM) v.1.4: formulation of an ocean general circulation model. Geosci. Model Dev. 7, 663-693 (2014).

70. Wekerle, C. et al. Eddy-Resolving Simulation of the Atlantic Water Circulation in the Fram Strait With Focus on the Seasonal Cycle. J. Geophys. Res. Ocean. 122, 8385-8405 (2017). 


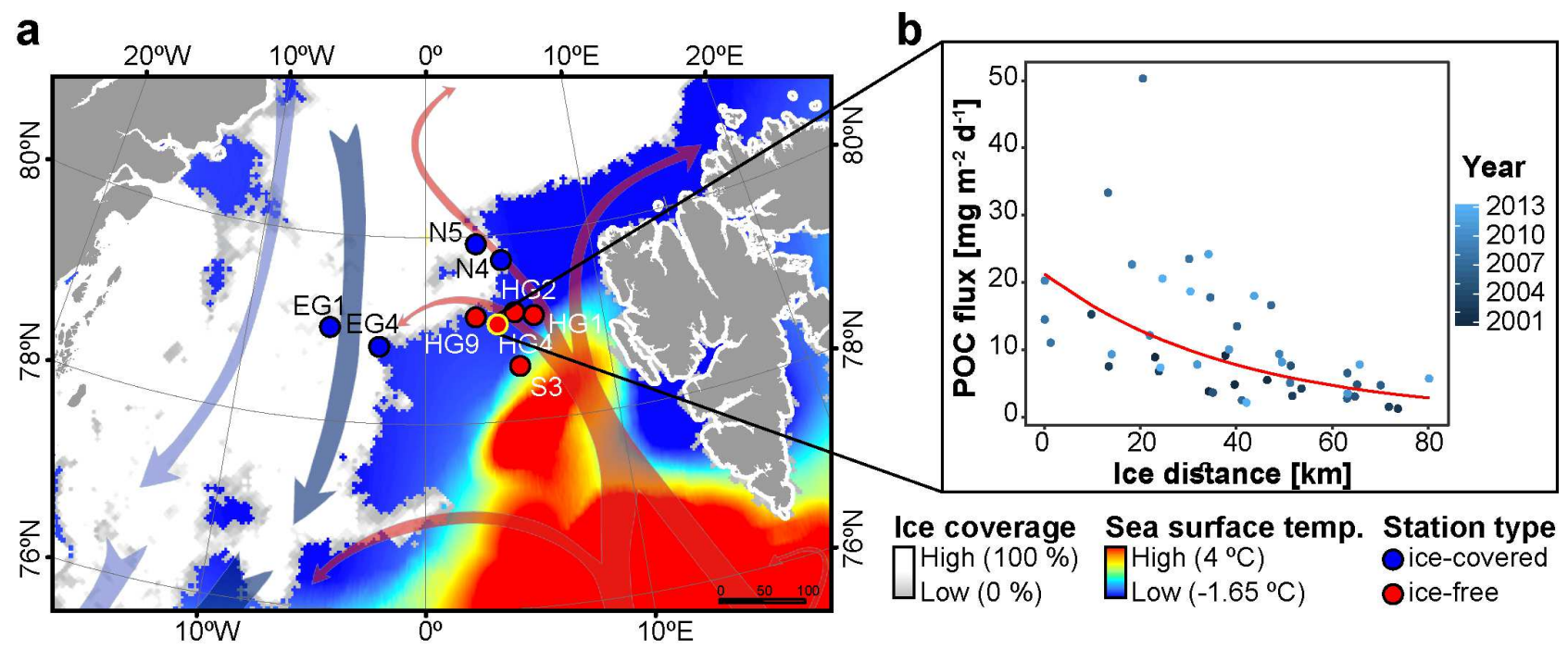

720 Figure 1. Overview of sampling area in the Fram Strait. (a) Monthly average of sea-ice cover and 721 sea surface temperature during July 2016. The arrows represent general directions of the WSC (in red) and the EGC (in blue). The yellow edge of the HG4 station indicates the position of a long-term sediment trap deployment. (b) Particulate Organic Carbon (POC) flux collected at $200 \mathrm{~m}$ by a longterm moored sediment trap between 2001 and 2013 during the spring period between February and April, plotted as a function of the distance to the ice-edge. The regression shows that there was a significantly negative relationship between the distance to the ice-edge and the magnitude of POC flux $\left(\mathrm{R}^{2}=0.39, p<0.01\right)$. 

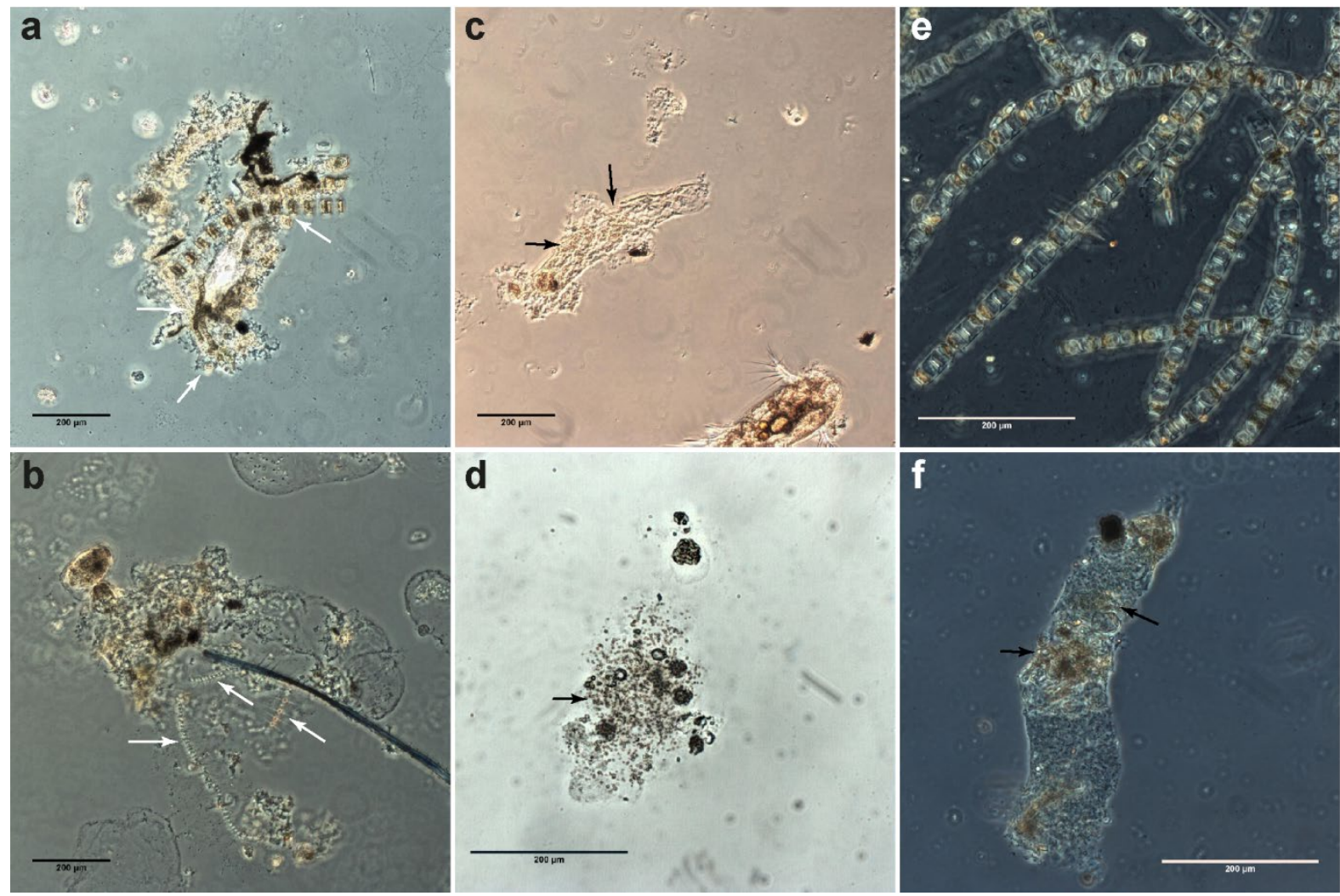

729 Figure 2. Exemplary light microscopy images of marine aggregates from MSC deployments in

730 Fram Strait. (a,b) Aggregates dominated by diatoms from ice-covered region -'EG', where (a) is 731 mainly diatoms and (b) is diatoms together with Phaeocystis spp. (c,d) Aggregates dominated by 732 flagellates in the ice-free region - ' $\mathrm{HG}$ ', where (c) is a copepod fecal pellet composed of flagellates 733 and (d) is a marine snow aggregate formed from Phaeocystis spp. colonies. (e) Chains of Melosira 734 spp., diatoms growing under the sea-ice. (f) Calanus spp. (copepod) fecal pellets collected at the ice735 covered region - ' $\mathrm{N}$ ' and formed from mainly Phaeocystis spp. colonies with a few diatoms. All scale 736 bars indicate $200 \mu \mathrm{m}$ long. White arrows point towards diatom chains and black arrows point towards 737 colonies of flagellates. 


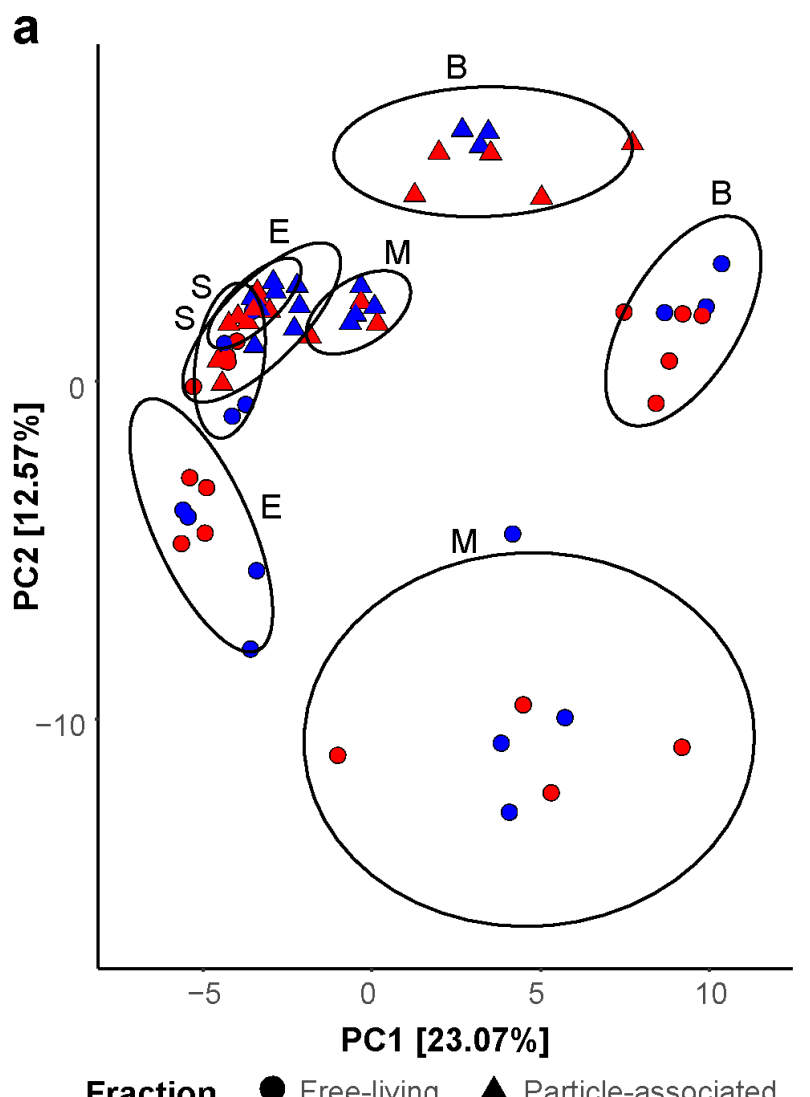

Fraction Free-living b

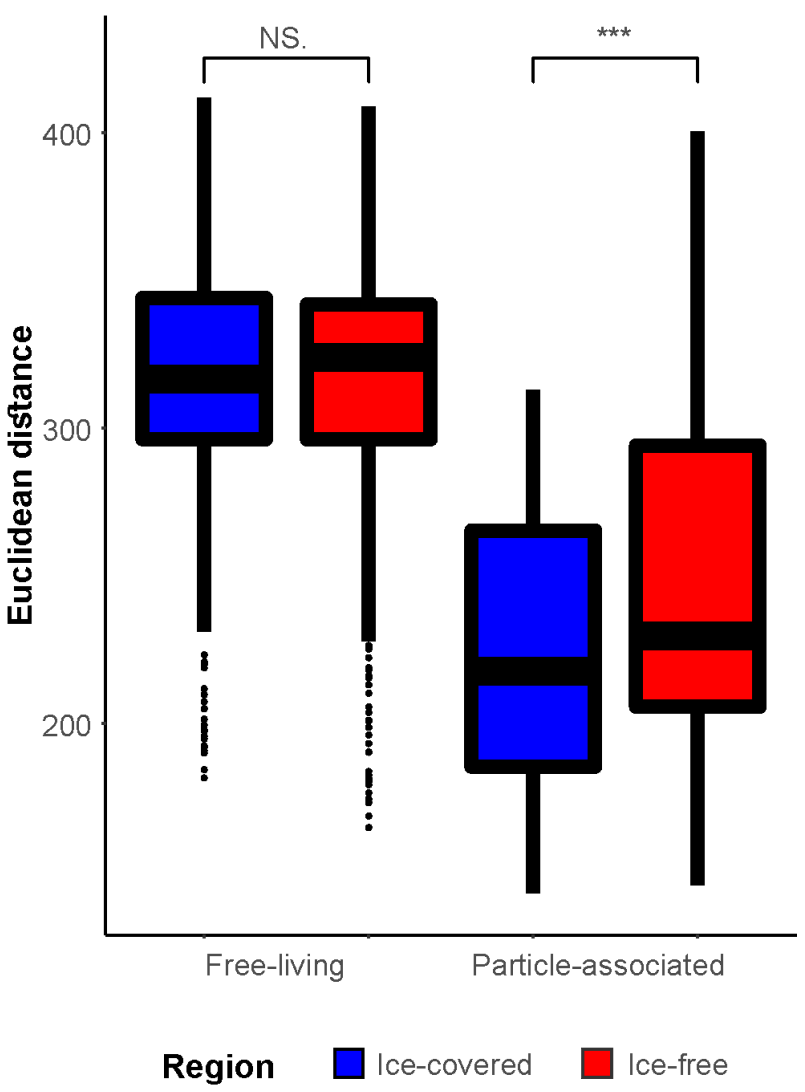

739 Figure 3. Free-living and particle-associated community patterns throughout the water column

740 of the Fram Strait. (a) Principal component analysis (PCA) of microbial communities. Ellipses 741 encompass clustering of each of the fractions by water layer (S-surface, E-epipelagic, Mmesopelagic, B-bathypelagic), with normal confidence of 0.95 . The percentages on both axes represent the explained variance of the axis. (b) Euclidean distances between microbial communities in each fraction along the entire water column. The colors represent different geographic origins: icecovered (blue) and ice-free (red) regions. (NS) - not significant (Wilcoxon signed-rank test; $p$ adjusted $>0.01) .(* * *)$ - significant (Wilcoxon signed-rank test; $p$-adjusted $<0.001$ ). 

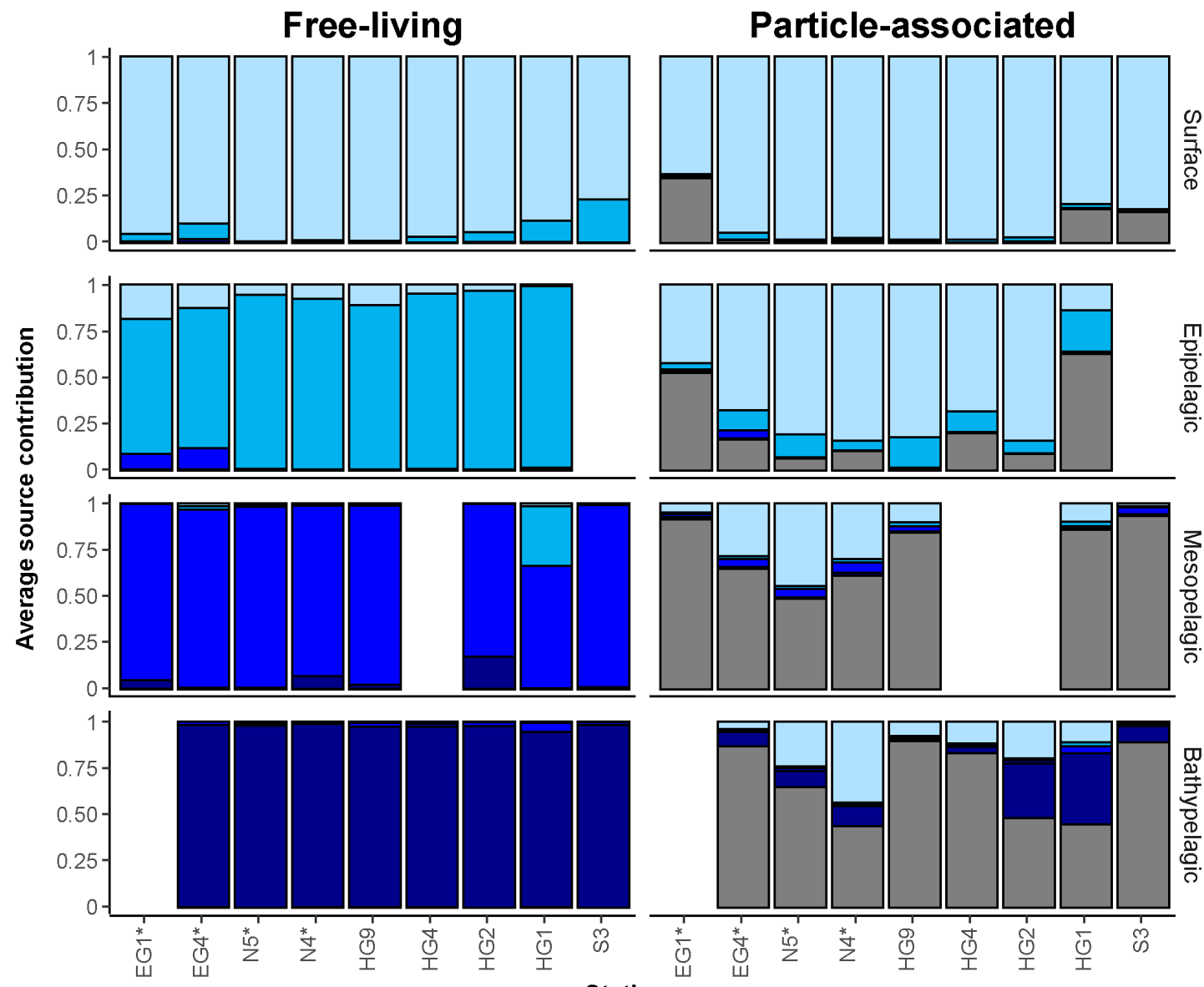

Source FL communities

Surface

Epipelagic

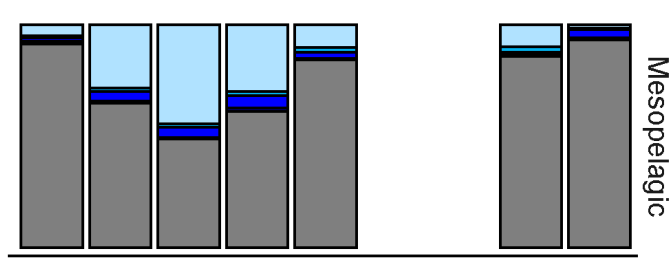

\section{3
$\mathbb{D}$
응
$\frac{0}{10}$
$\frac{0}{2}$
음.}

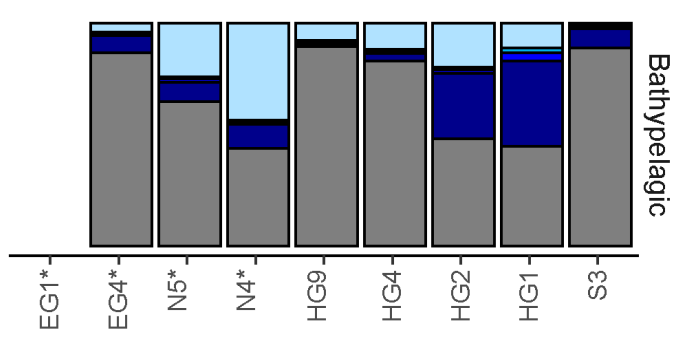

748 Figure 4. Proportion estimates of the source water masses for microbial communities in

749 different water layers, using 'SourceTracker'. The source estimates for each free-living (FL)

750 community was conducted estimated using leave-one-out approach (i.e., based on all other FL

751 communities; see methods), and the sources of the particle-associated (PA) communities were

752 estimated based on the FL communities. The ice-covered stations are marked with an asterisk. 

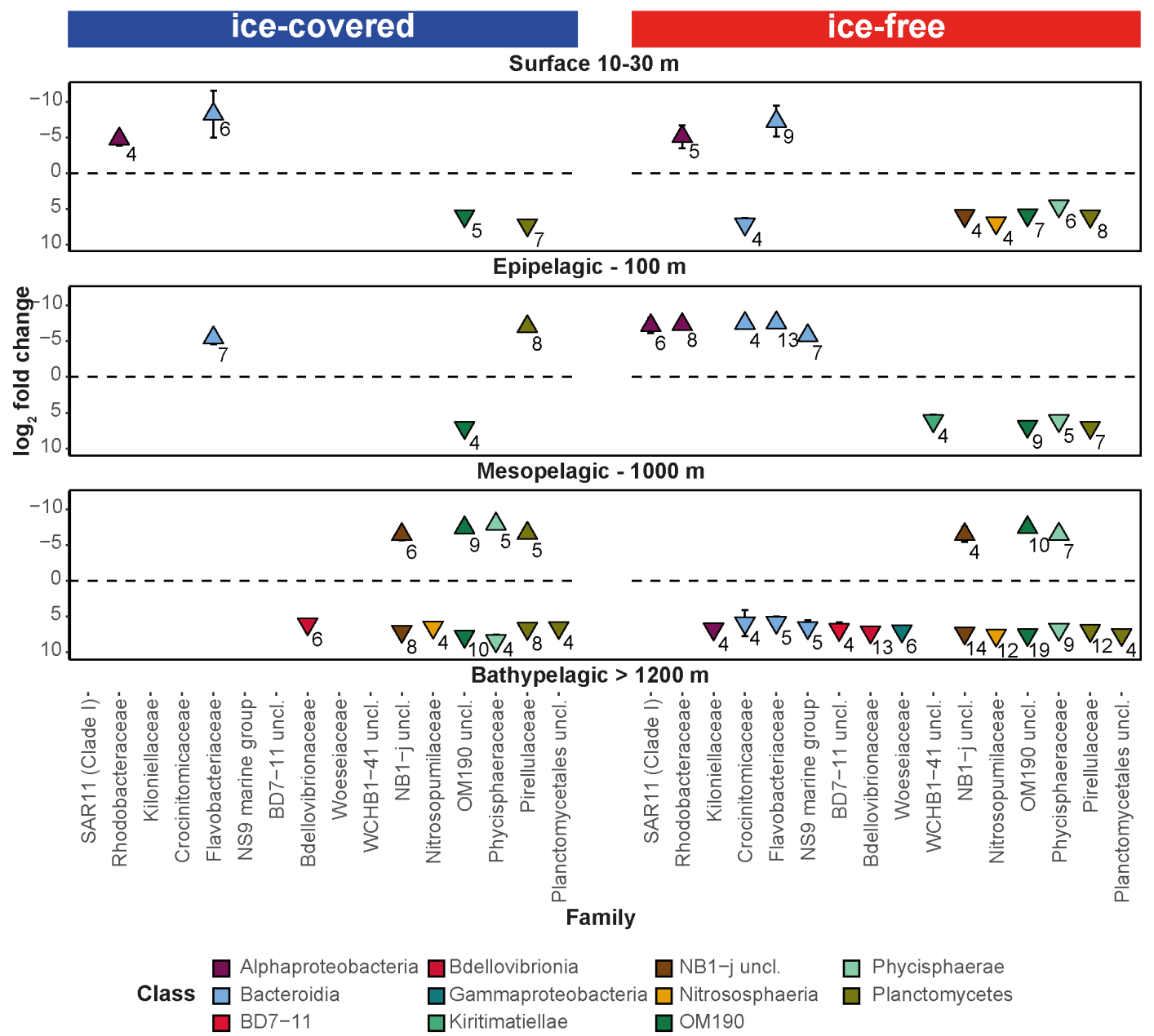

754 Figure 5. Differences in particle-associated (PA) community composition between the distinct 755 water layers, in ice-covered and ice-free regions. Enriched taxonomic families between each two consecutive depths (surface-epipelagic, epipelagic-mesopelagic and mesopelagic-bathypelagic), ordered according to labels between the panels. The y-axis represents the mean $\log _{2}$ fold change for microbial families with more than 3 ASVs with $\log _{2}$ fold change absolute value higher than 1

759 (standard error is smaller than the point). Positive value represent enrichment in deeper water layers and negative value represents enrichment in shallower water layer. The numbers near the symbols represent the number of ASVs enriched in the depth. The x-axis is ordered according to the different taxonomic classes, represented by the color code. 


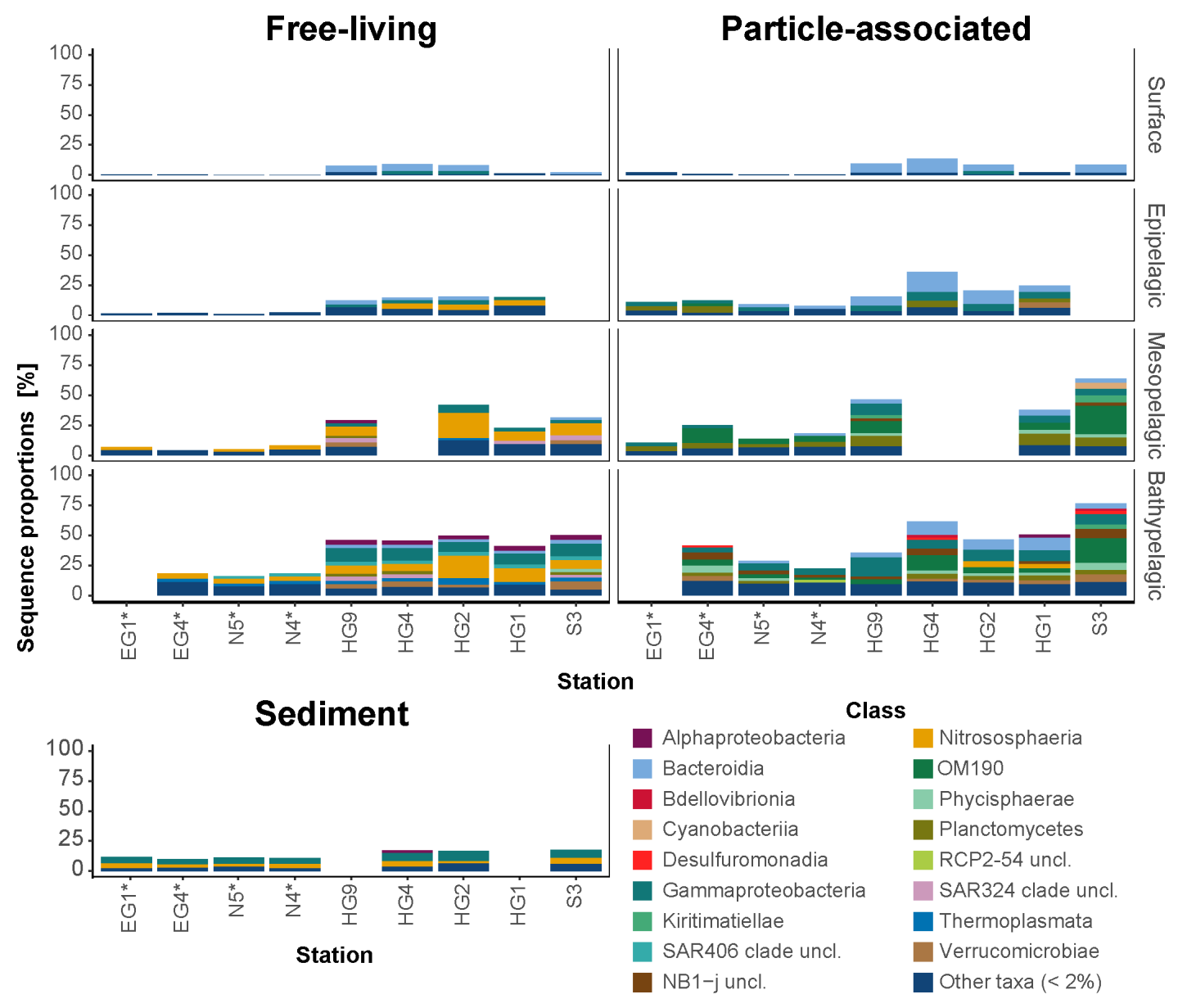
764 Figure 6. Overview of the sequence proportion of enriched ASVs in the free-living, particle-
765 associated, and uppermost centimeter of deep-sea sediment microbial communities. The classes 766 represented by colors according to the legend, all classes with sequence proportion below $2 \%$ were 767 classified as "Other classes". The ice-covered stations are marked with an asterisk. 
Table 1: Sinking aggregate trajectories characteristics of particles reaching the surface ocean between March $1^{\text {st }} 2016$ and July $31^{\text {st }} 2016$ in different regions of Fram Strait. The sinking trajectories were modeled using the measured in situ aggregates sinking velocities in each region, as well as using hypothetical low $\left(20 \mathrm{~m} \mathrm{~d}^{-1}\right)$ and high $\left(60 \mathrm{~m} \mathrm{~d}^{-1}\right)$ velocities. The values after \pm represent standard deviation.

\begin{tabular}{|c|c|c|c|}
\hline & EG & $\mathbf{N}$ & HG \\
\hline Station coordinates & $\begin{array}{l}78.81^{\circ} \mathrm{N} / \\
2.729^{\circ} \mathrm{W}\end{array}$ & $\begin{array}{l}79.74^{\circ} \mathrm{N} / \\
4.185^{\circ} \mathrm{E}\end{array}$ & $\begin{array}{l}79.06^{\circ} \mathrm{N} / 4.51^{\circ} \\
\mathrm{E}\end{array}$ \\
\hline Starting depth $(\mathrm{m})$ of trajectory calculation & 2350 & 2350 & 1950 \\
\hline Number of days during 2016 with ice-coverage $>15 \%$ & 197 & 107 & 78 \\
\hline $\begin{array}{l}\text { Number of days during March - July } 2016 \text { with ice-coverage } \\
>15 \%\end{array}$ & 92 & 38 & 29 \\
\hline Measured sinking velocity $\left(\mathrm{m} \mathrm{d}^{-1}\right)$ & 52 & 52 & 29 \\
\hline Median catchment radius $(\mathrm{km})$ & $78 \pm 45$ & $74 \pm 53$ & $118 \pm 97$ \\
\hline $\begin{array}{l}\text { Aggregates originated from ice-covered waters } \\
(\% \text { of total })^{*}\end{array}$ & 72 & 44 & 16 \\
\hline Median sinking trajectory length $(\mathrm{km})$ & $194 \pm 62$ & $181 \pm 64$ & $392 \pm 111$ \\
\hline Low sinking velocity $\left(\mathrm{m} \mathrm{d}^{-1}\right)$ & 20 & 20 & 20 \\
\hline Median catchment radius $(\mathrm{km})$ & $142 \pm 79$ & $132 \pm 115$ & $124 \pm 124$ \\
\hline Aggregates originated from ice-covered waters ( $\%$ of total)* & 50 & 36 & 15 \\
\hline Median sinking trajectory length $(\mathrm{km})$ & $536 \pm 124$ & $527 \pm 159$ & $572 \pm 175$ \\
\hline High sinking velocity $\left(\mathrm{m} \mathrm{d}^{-1}\right)$ & 60 & 60 & 60 \\
\hline Median catchment radius $(\mathrm{km})$ & $70 \pm 46$ & $70 \pm 53$ & $94 \pm 76$ \\
\hline Aggregates originated in ice-covered waters ( $\%$ of total)* & 74 & 41 & 6 \\
\hline Median sinking trajectory length $(\mathrm{km})$ & $179 \pm 55$ & $161 \pm 63$ & $233 \pm 71$ \\
\hline
\end{tabular}


Table 2: Vertical fluxes and marine aggregates characteristics in the epipelagic waters (0-100

m) of ice-covered and ice-free regions. ESD: equivalent spherical diameter. The values after \pm represent standard errors.

\begin{tabular}{|c|c|c|}
\hline & ice-covered region & ice-free region \\
\hline \multicolumn{3}{|l|}{ Drifiting traps fluxes } \\
\hline Particulate organic carbon (POC; $\mathrm{mg} \mathrm{m}^{-2} \mathrm{~d}^{-1}$ ) & 60 & 32 \\
\hline Particulate organic nitrogen $\left(\mathrm{PON} ; \mathrm{mg} \mathrm{m}^{-2} \mathrm{~d}^{-1}\right)$ & 9 & 3 \\
\hline POC to PON ratio (mol:mol) & 8 & 12 \\
\hline \multicolumn{3}{|l|}{ Gel trap fluxes } \\
\hline Number of particles & 2003 & 1399 \\
\hline Total particle number flux $\left(\# \mathrm{~m}^{-2} \mathrm{~d}^{-1}\right.$ ) & $36 \times 10^{4}$ & $37 \times 10^{4}$ \\
\hline Total particle volume flux $\left(\mathrm{mm}^{3} \mathrm{~m}^{-2} \mathrm{~d}^{-1}\right)$ & $11 \times 10^{3}$ & $1.5 \times 10^{3}$ \\
\hline Average ESD of particles (mm) & $0.2 \pm 0.2$ (range: $0.1-2$ ) & $\begin{array}{l}0.1 \pm 0.1 \text { (range: } 0.1 \\
-1 \text { ) }\end{array}$ \\
\hline Average volume of particles $\left(\mathrm{mm}^{3}\right)$ & $0.03 \pm 0.2$ & $0.003 \pm 0.02$ \\
\hline \multicolumn{3}{|l|}{ Vertical flow chamber } \\
\hline Number of collected particles & 36 & 24 \\
\hline Average ESD of particles (mm) & $0.9 \pm 0.1$ (range: $0.3-2.4)$ & $\begin{array}{l}0.6 \pm 0.1 \text { (range: } 0.3 \\
-1.3 \text { ) }\end{array}$ \\
\hline Average sinking velocity of particles $\left(\mathrm{m} \mathrm{d}^{-1}\right)$ & $52.8 \pm 0.9$ & $29.5 \pm 0.7$ \\
\hline Dominant phytoplankton in particles & Diatoms & $\begin{array}{l}\text { Flagellates } \\
\text { (Phaeocystis spp.) }\end{array}$ \\
\hline
\end{tabular}




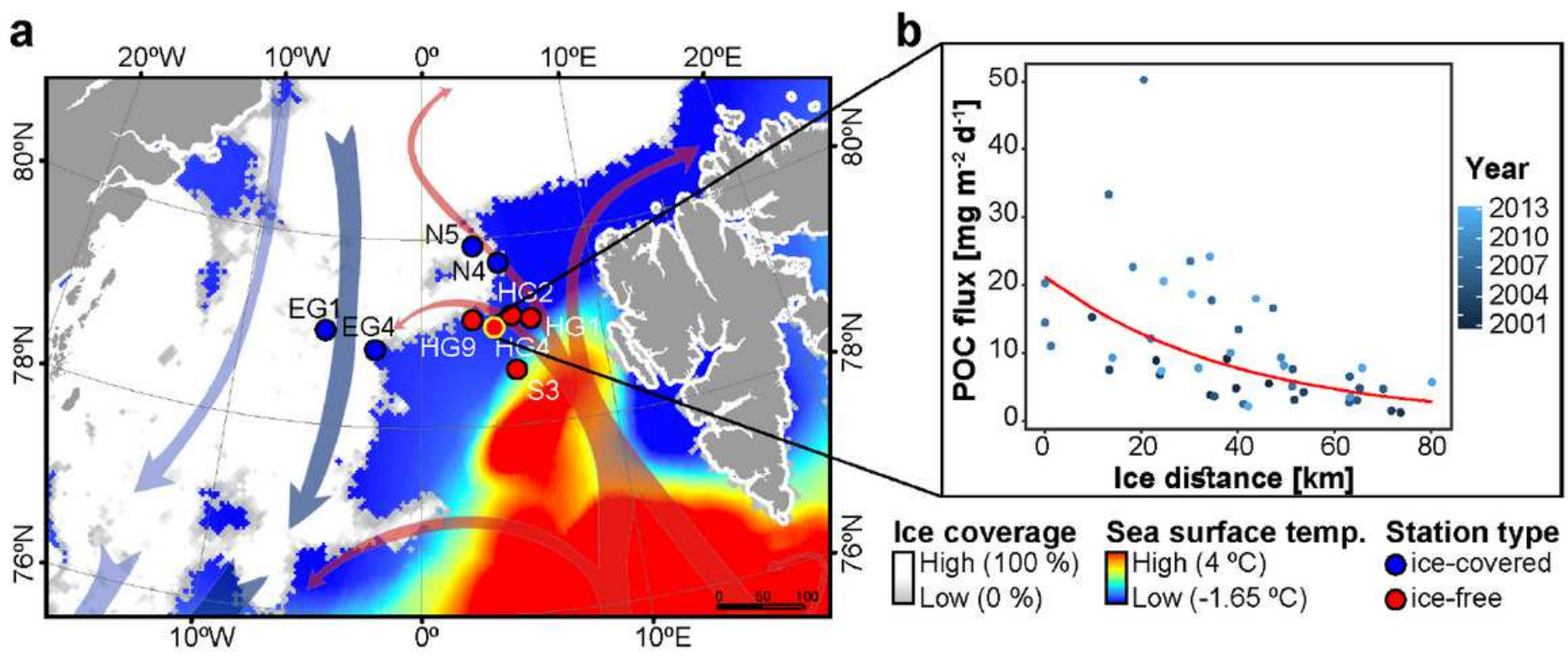

Figure 1

Overview of sampling area in the Fram Strait. (a) Monthly average of sea-ice cover and sea surface temperature during July 2016. The arrows represent general directions of the WSC (in red) and the EGC (in blue). The yellow edge of the HG4 station indicates the position of a long-term sediment trap deployment. (b) Particulate Organic Carbon (POC) flux collected at $200 \mathrm{~m}$ by a long-term moored sediment trap between 2001 and 2013 during the spring period between February and April, plotted as a function of the distance to the ice-edge. The regression shows that there was a significantly negative relationship between the distance to the ice-edge and the magnitude of $P O C$ flux $(R 2=0.39, p<0.01)$. 

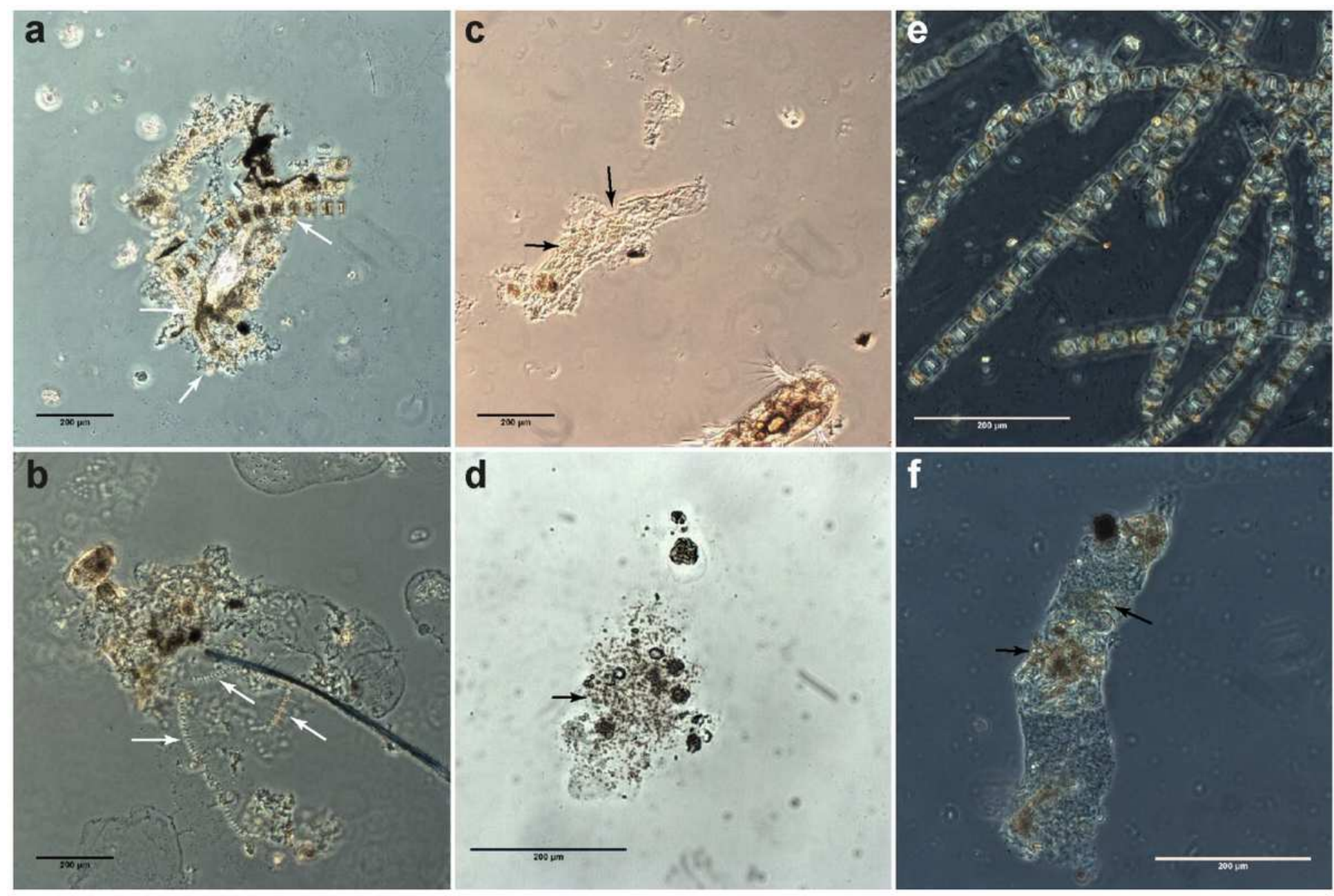

\section{Figure 2}

Exemplary light microscopy images of marine aggregates from MSC deployments in Fram Strait. $(a, b)$ Aggregates dominated by diatoms from ice-covered region -'EG', where (a) is mainly diatoms and (b) is diatoms together with Phaeocystis spp. (c,d) Aggregates dominated by flagellates in the ice-free region ' $H G$ ', where (c) is a copepod fecal pellet composed of flagellates and (d) is a marine snow aggregate formed from Phaeocystis spp. colonies. (e) Chains of Melosira spp., diatoms growing under the sea-ice. (f) Calanus spp. (copepod) fecal pellets collected at the ice-covered region - ' $N$ ' and formed from mainly Phaeocystis spp. colonies with a few diatoms. All scale bars indicate $200 \mu \mathrm{m}$ long. White arrows point towards diatom chains and black arrows point towards colonies of flagellates. 


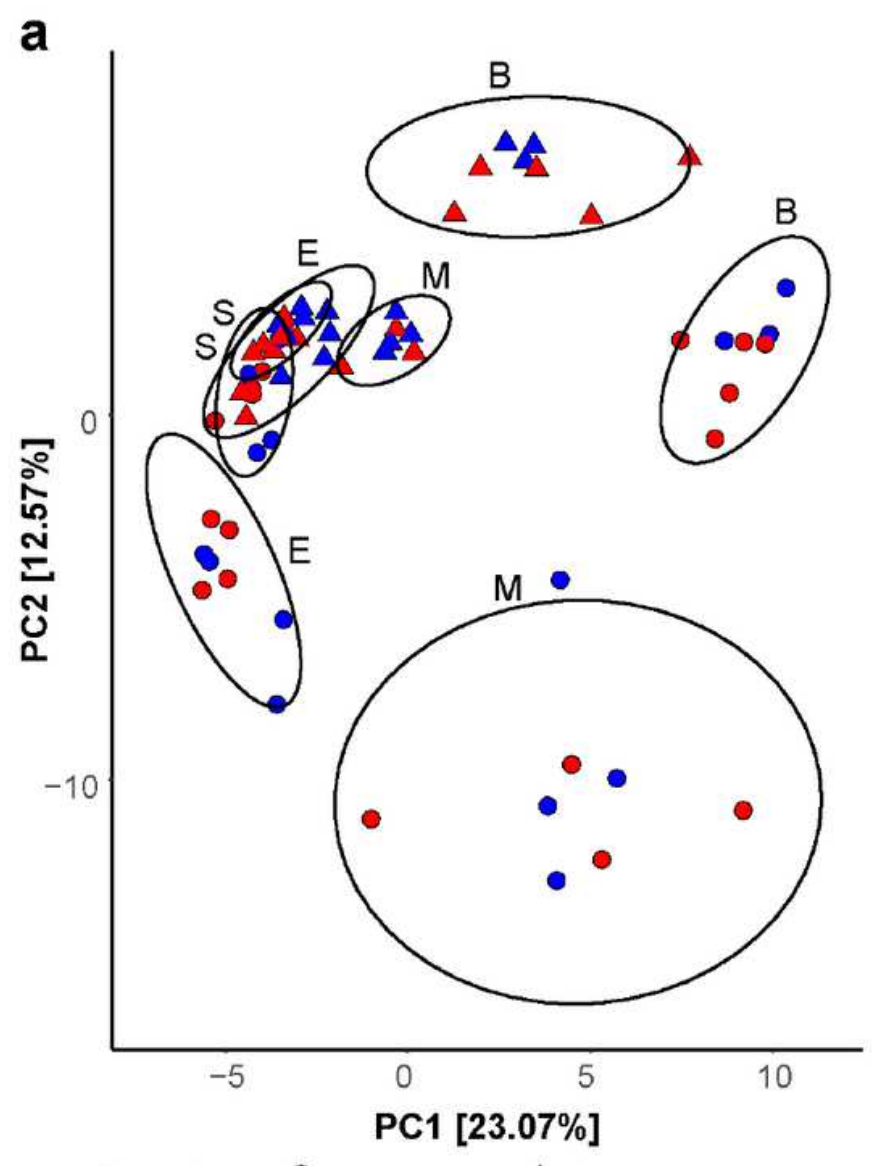

Fraction b

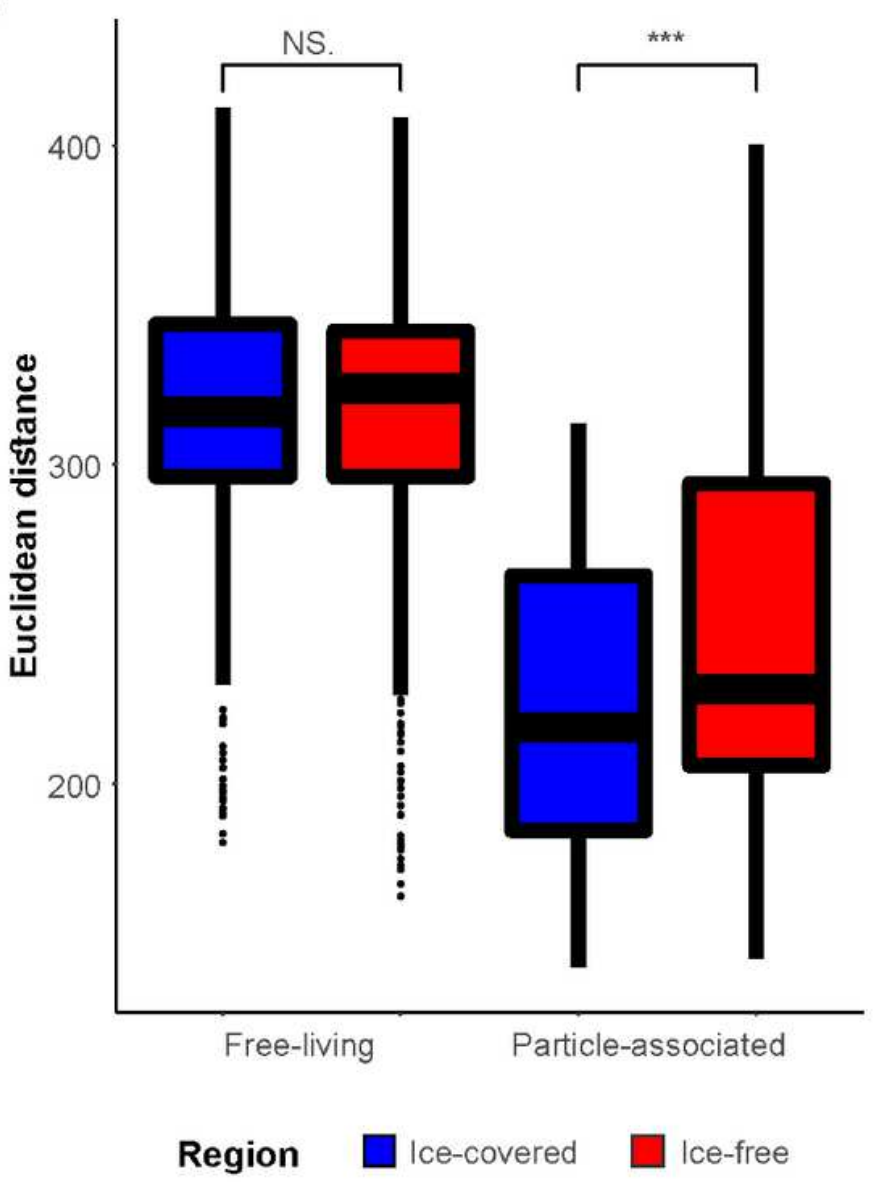

Figure 3

Free-living and particle-associated community patterns throughout the water column of the Fram Strait. (a) Principal component analysis (PCA) of microbial communities. Ellipses encompass clustering of each of the fractions by water layer (S-surface, E-epipelagic, M-mesopelagic, B-bathypelagic), with normal confidence of 0.95 . The percentages on both axes represent the explained variance of the axis. (b) Euclidean distances between microbial communities in each fraction along the entire water column. The colors represent different geographic origins: ice-covered (blue) and ice-free (red) regions. (NS) - not significant (Wilcoxon signed-rank test; $p$-adjusted>0.01). ( $\left.{ }^{(\star \star}\right)$ - significant (Wilcoxon signed-rank test; $p$ adjusted<0.001). 
Free-living
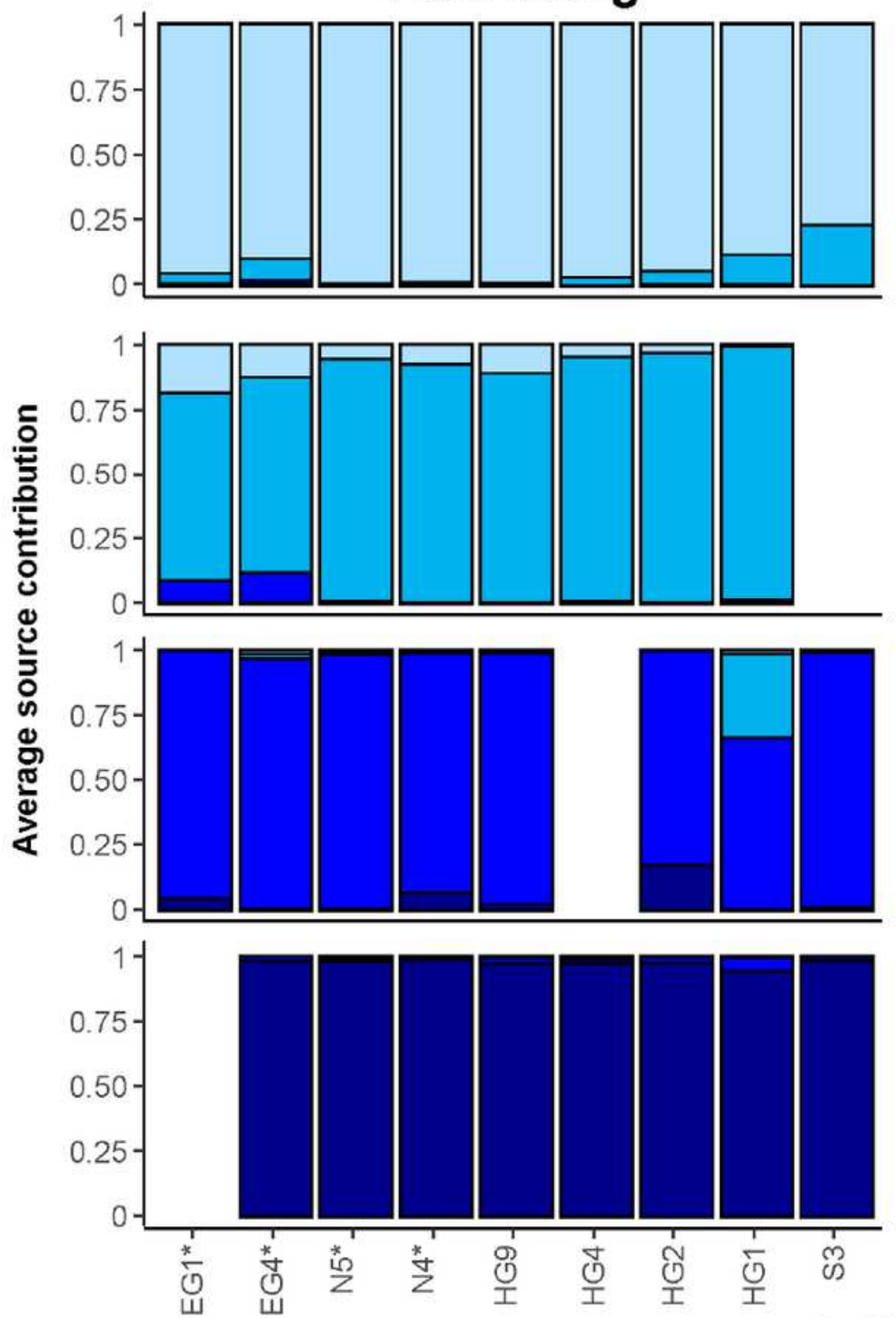

Particle-associated
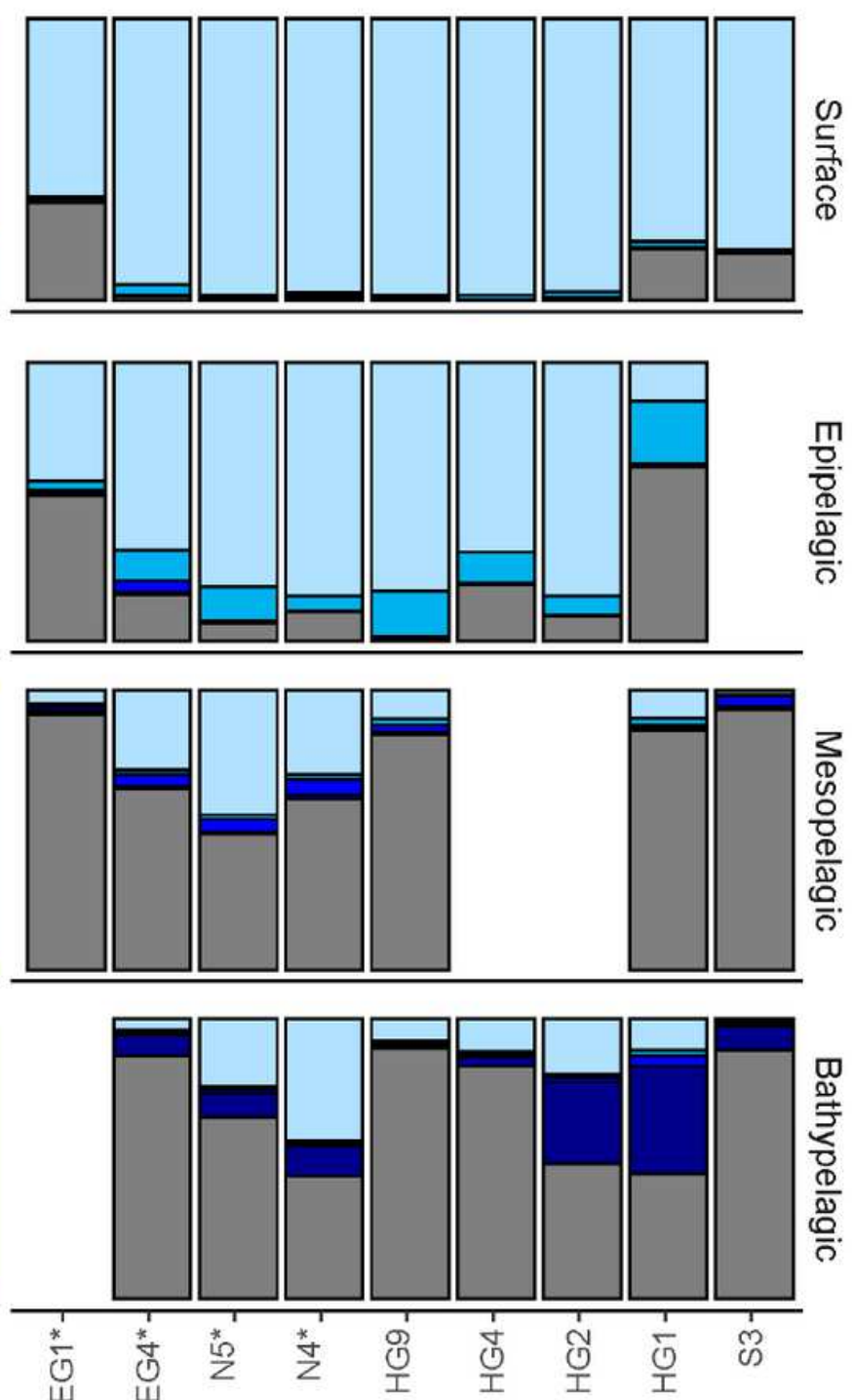

\section{Station}

Source FL communities

Surface

$\square$ Epipelagic

Mesopelagic

Bathypelagic

Unknown

Figure 4

Proportion estimates of the source water masses for microbial communities in different water layers, using 'SourceTracker'. The source estimates for each free-living (FL) community was conducted estimated using leave-one-out approach (i.e., based on all other FL communities; see methods), and the sources of the particle-associated (PA) communities were estimated based on the FL communities. The ice-covered stations are marked with an asterisk. 


\section{ice-covered}

Surface $10-30 \mathrm{~m}$

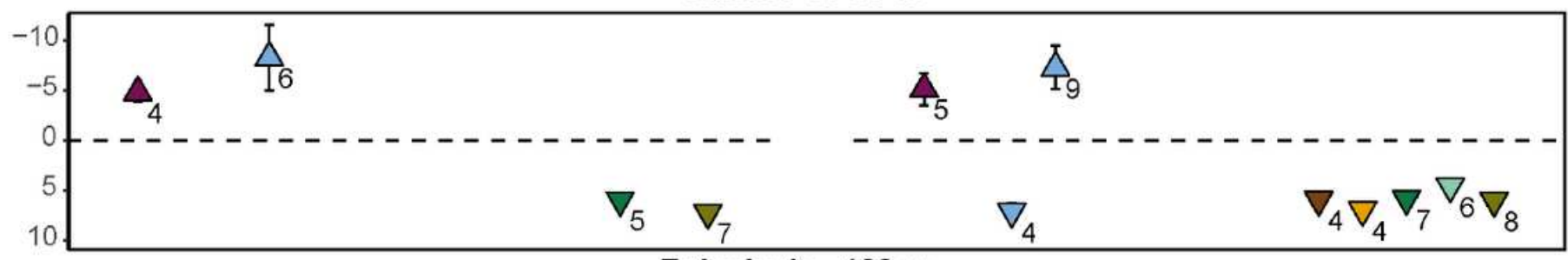

Epipelagic - $100 \mathrm{~m}$

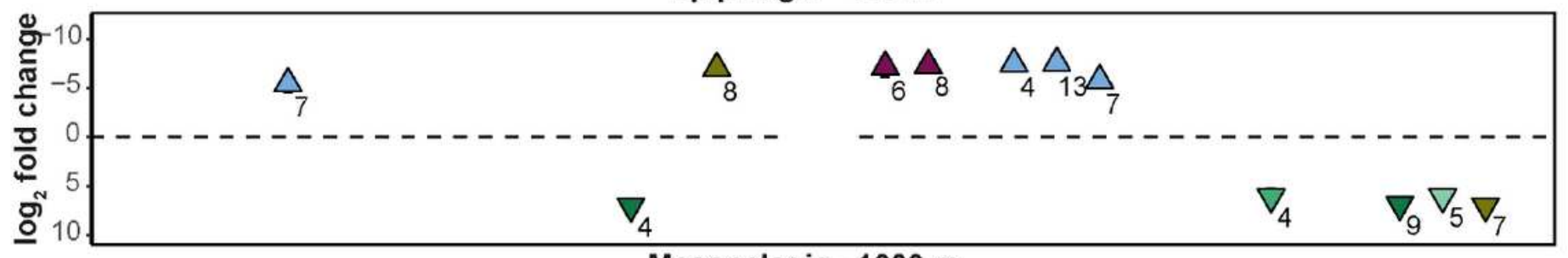

Mesopelagic - $1000 \mathrm{~m}$

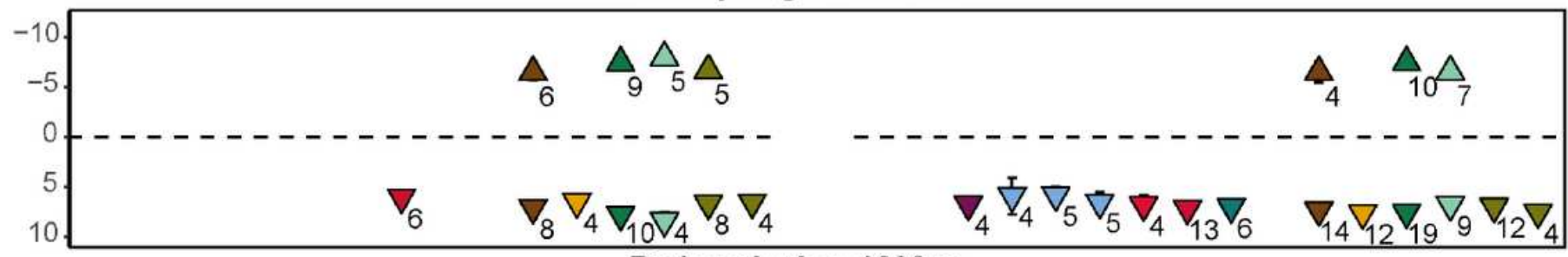

\section{Bathypelagic $>1200 \mathrm{~m}$}

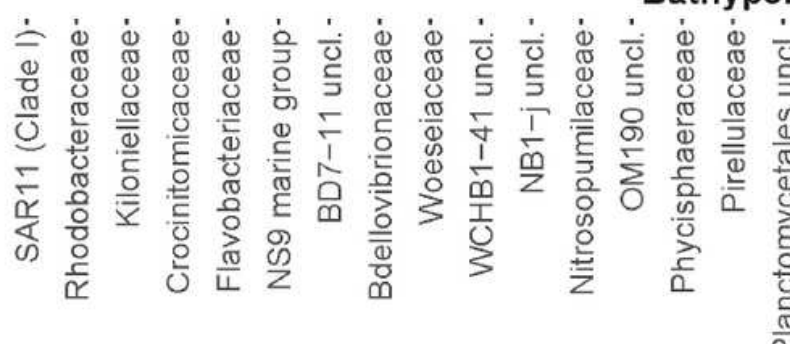

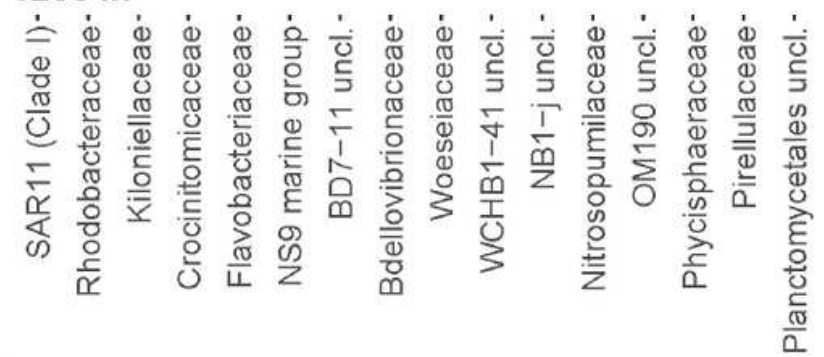

Family

\begin{tabular}{|c|c|c|c|c|}
\hline Iacc & $\square$ Alphaproteobacteria & $\square$ Bdellovibrionia & $\square$ NB1-j uncl. & $\begin{array}{l}\square \text { Phycisphaerae } \\
\square \text { Planctomycetes }\end{array}$ \\
\hline lass & $\begin{array}{l}\square \text { Bacteroıdıa } \\
\square \text { BD7-11 }\end{array}$ & $\begin{array}{l}\square \text { Gammaproteobacteria } \\
\square \text { Kiritimatiellae }\end{array}$ & $\begin{array}{l}\square \text { Nitrososphaeria } \\
\square \text { OM190 }\end{array}$ & \\
\hline
\end{tabular}

\section{Figure 5}

Differences in particle-associated (PA) community composition between the distinct water layers, in icecovered and ice-free regions. Enriched taxonomic families between each two consecutive depths (surface-epipelagic, epipelagic-mesopelagic and mesopelagic-bathypelagic), ordered according to labels between the panels. The $y$-axis represents the mean log2 fold change for microbial families with more than 3 ASVs with log2 fold change absolute value higher than 1 (standard error is smaller than the point). Positive value represent enrichment in deeper water layers and negative value represents enrichment in shallower water layer. The numbers near the symbols represent the number of ASVs enriched in the depth. The $x$-axis is ordered according to the different taxonomic classes, represented by the color code. 

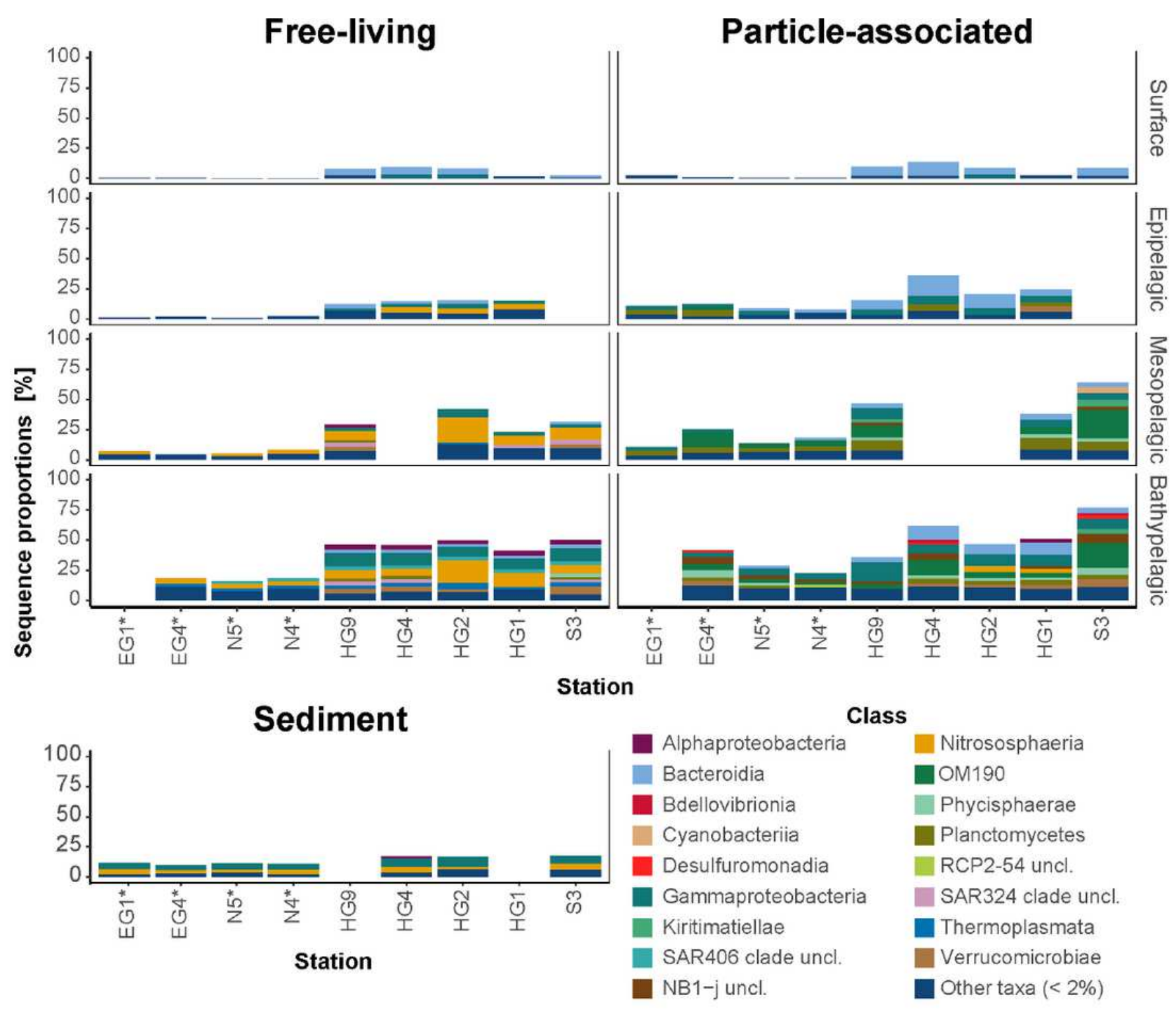

Figure 6

Overview of the sequence proportion of enriched ASVs in the free-living, particle-associated, and uppermost centimeter of deep-sea sediment microbial communities. The classes represented by colors according to the legend, all classes with sequence proportion below $2 \%$ were classified as "Other classes". The ice-covered stations are marked with an asterisk.

\section{Supplementary Files}

This is a list of supplementary files associated with this preprint. Click to download.

- Fadeevetalsupp.pdf 